\title{
Transition-metal Nanoparticles in Catalysis: From Historical Background to the State-of-the Art
}

\author{
Didier Astruc
}

\section{1}

\section{Introduction}

The nanosciences have recently evolved as a major research direction of our modern Society resulting from an ongoing effort to miniaturize at the nanoscale processes that currently use microsystems. Towards this end, it is well admitted that the bottom-up approach should now replace the classic top-down one, a strategic move that is common to several areas of nanosciences including optoelectronics, sensing, medicine and catalysis. The latter discipline certainly is the key one for the development of starting chemicals, fine chemicals and drugs from raw materials. During the twentieth century, chemists have made considerable achievements in heterogeneous catalysis [1], whereas homogeneous catalysis [2] progressed after the second world war (hydroformylation) and especially since the early 1970s (hydrogenation). Heterogeneous catalysis, that benefits from easy removal of catalyst materials and possible use of high temperatures, suffered for a long time from lack of selectivity and understanding of the mechanistic aspects that are indispensable for parameter improvements. Homogeneous catalysis is very efficient and selective, and is used in a few industrial processes, but it suffers from the impossibility of removal of the catalyst from the reaction media and its limited thermal stability. Green catalysis aspects now obviously require that environmentally friendly (for instance phosphine-free) catalysts be designed for easy removal from the reaction media and recycling many times with very high efficiency. These demanding conditions bring a new research impetus for catalyst development at the interface between homogeneous and heterogeneous catalysis, gathering the sophisticated fulfilment of all the constraints that were far from being fully taken into account by the pioneers and even the specialists in each catalytic discipline in the former decades. Yet the considerable knowledge gained from the past research in homogeneous, heterogeneous, supported and biphasic catalysis, including also studies in nonclassical conditions (solvent-free, aqueous, use of ionic liquids, fluorine chemistry, microemulsions, micelles, reverse micelles, vesicles, surfactants, aerogels, 
polymers or dendrimers), should now help establish the desired optimized catalytic systems.

In this context, the use of transition-metal nanoparticles (NPs) in catalysis [3] is crucial as they mimic metal surface activation and catalysis at the nanoscale and thereby bring selectivity and efficiency to heterogeneous catalysis. Transitionmetal NPs are clusters containing from a few tens to several thousand metal atoms, stabilized by ligands, surfactants, polymers or dendrimers protecting their surfaces. Their sizes vary between the order of one nanometer to several tens or hundreds of nanometers, but the most active in catalysis are only one or a few nanometers in diameter, i.e. they contain a few tens to a few hundred atoms only [4]. This approach is also relevant to homogeneous catalysis, because there is a full continuum between small metal clusters and large metal clusters, the latter being also called colloids, sols or NPs. NPs are also well soluble in classic solvents (unlike metal chips in heterogeneous catalysis) and can often be handled and even characterized as molecular compounds by spectroscopic techniques that are well known to molecular chemists, such as ${ }^{1} \mathrm{H}$ and multinuclear NMR, infrared and UV-vis spectroscopy and cyclic voltammetry. Molecular mechanisms involving the NP surfaces in catalytic reactions are much more difficult to elucidate, however, than those of monometallic catalysts, and the size and shape of the NP catalysts are key aspects of the catalytic steps. NPs themselves can also be used as catalysts in homogeneous systems or alternatively they can be heterogenized by fixation onto a heterogeneous support such as silica, alumina, other oxides or carbon, for instance carbon nanotubes. Thus, the field of NP catalysis involves both the homogeneous and heterogeneous catalysis communities, and these catalysts are sometimes therefore called "semi-heterogeneous" [3, 5]. This field has attracted a considerable amount of attention recently, as demonstrated by the burgeoning number of publications in all kinds of catalytic reactions, because NP catalysts are selective, efficient, and recyclable and thus meet the modern requirements for green catalysts. Applications are already numerous, and the use of these catalysts in industry will obviously considerably expand in the coming years. Table 1.1 shows the impressive number of catalytic reactions that have been achieved using transition-metal NPs under rather mild conditions.

The stabilization of NPs during their synthesis can be electrostatic, steric, electrosteric (combination of steric and electrostatic, see Fig. 1.1) or by ligands [4, 5, $8,11]$. The NP synthesis can also occasionally be carried out from metals by atomic metal vaporization or from metal(0) complexes [11]. In view of the catalyst recycling, NP catalysts are often immobilized or grafted onto inorganic or organic polymer supports $[4,5,8,11]$. The mechanism of transition-metal NP selfassembly has recently been subjected to detailed studies by Finke's group with a proposal of a four-step nucleation mechanism including two autocatalytic steps $[11 \mathrm{k}]$. Such mechanistic studies are of fundamental interest for NP catalysis overall.

There are many reviews on the multiple NP synthetic modes [4-11], and here we will not systematically detail this aspect per se. We concentrate our attention on catalysis, from the pioneering studies to the present state of the art. 
Table 1.1 Reactions catalyzed by transition-metal nanoparticles.

\section{Reaction}

Hydrogenation

Simple olefins and dienes

Alkynes
$\mathrm{CO}_{2}$
Arene ring
Arene rings of dibenzo-18-crown-6-ether
Acrolein
Methylacrylate
Allylic alcohols
N-isopropylacrylamide
Ethylpyruvate
Citral
Styrene
Trans-stilbene
Opening of epoxides
Dehydrolinalol
Citronellal
9-Decen-1-ol
Various olefins including functional ones
Polar olefins
Nitroaromatics
Ketones, benzonitrile
Cinnamaldehyde
Asymmetric hydrogenation

Heck C-C coupling (ArX + olefin $\rightarrow$ arylolefin)

References (see also general Refs. 3-11)

2, 6b, 10d-i, 12, 14d,f,j,k,1, 16, 17a,b,d, 23, 26, 311,o-q, 32, 33, 35a,i, 36a, 40a, 41, $43 \mathrm{~d}, 44 \mathrm{~b}, \mathrm{~h}, 46 \mathrm{a}-\mathrm{d}, 58,61$

14c, 37b, 39, 40b, 62, 63

10,82

12a, 29, 33k,m, 34, 37b, 65-70

64

$12 \mathrm{~b}, 78$

16

$14 d, 17 b$

$17 \mathrm{~b}$

30a, 63

$32 \mathrm{c}, \mathrm{d}, \mathrm{e}$

$18 \mathrm{i}$

$32 \mathrm{~h}, \mathrm{f}$

$14 \mathrm{a}$

$14 \mathrm{~b}$

$59 \mathrm{~b}$

$35 n$

9f,g; 14e, 22b,d, 32h, 33k,m

$22 \mathrm{~b}$

9a, 59c, 60, 61

14h, 331, 35d,i

47, 59a

29

7, 8b, 14f, 17f, 18i, 22, 24a, 31a-n, 32n, 33e-g,i,j, 35g,n, 40b, 43a-f, 44a-k, 53, $71,72,73$

13a,b, 14i, 17i-k, 21, 22, 23, 24a, 25, 26, 27, 31m,n, 33e,h,i 34b, 35b,o, 43c, 44c-e,1, 54, 72f, 74a, 76

Sonogashira $\mathrm{C}-\mathrm{C}$ coupling

(ArX + alkyne $\rightarrow$ arylalkyne)

Stille $\mathrm{C}-\mathrm{C}$ coupling ( $\left.\mathrm{ArX}+\mathrm{Bu}_{3} \mathrm{SnR} \rightarrow \mathrm{Ar}-\mathrm{R}\right)$

$33 \mathrm{~h}$

Negishi $\mathrm{C}-\mathrm{C}$ coupling ( $\mathrm{ArCl}+\mathrm{RZnX} \rightarrow \mathrm{Ar}-\mathrm{R})$

$44 \mathrm{~m}$

Kumada $\mathrm{C}-\mathrm{C}$ coupling (ArCl+RMgX(Ar-R)

$44 \mathrm{j}, \mathrm{k}$

Dehydrohalogenation of aryl halides

$44 \mathrm{i}, \mathrm{n}$

Amination of aryl halides and sulfonates $($ ArX + RNHR' $\rightarrow$ Ar-N(R)R')

Hydrosilylation

44k-o, 74b, 77

9h, 49a

28a,b

75 
Table 1.1 Continued

\begin{tabular}{ll}
\hline Reaction & References (see also general Refs. 3-11) \\
\hline$[3+2]$ Cycloaddition & 55 \\
McMurry coupling & 56,57 \\
Oxidation & \\
CO & $8 \mathrm{a}, 9 \mathrm{~d}, \mathrm{e}, 11 \mathrm{j}, 17,34,36 \mathrm{a}, \mathrm{b}, \mathrm{e}, 37 \mathrm{c}, \mathrm{d}, 45$, \\
& $51 \mathrm{~b}, 80$ \\
Dihydrogen & $46 \mathrm{e}$ \\
Aromatic amines & $33 \mathrm{~g}, 46 \mathrm{f}$ \\
Alkyl amines & $9 \mathrm{~d}$ \\
1-Phenylethanol & 38 \\
CH $\mathrm{H}_{3}$ OH and alcohol electro-oxidation & 47 \\
Cyclooctane & $49 \mathrm{~b}$ \\
Cyclohexane & $46 \mathrm{~g}$ \\
Ethene and propene epoxidation & 50 \\
Glucose & $52,46 \mathrm{~h}$ \\
Diol, Glycerol, ethylene glycol & $46 \mathrm{c}, \mathrm{e}, 81$ \\
Oxalate & $46 \mathrm{~h}$ \\
Amination & $24 \mathrm{~b}, 43 \mathrm{j}$ \\
Carbonylation & \\
Aryl halides & $24 \mathrm{~b}$ \\
Methanol & $53 \mathrm{a}$ \\
Allylic alkylation & $30 \mathrm{f}, 31,35 \mathrm{c}, 57$ \\
Mannich & 57 \\
Pauson-Khand & $11 \mathrm{~h}, 35 \mathrm{c}$ \\
Hydroconversion of hydrocarbons & $40 \mathrm{a}$ \\
Combustion: alkanes, arenes, alcohols & $32 \mathrm{e}, 35 \mathrm{j}, 79$ \\
Methanol reforming & $36 \mathrm{c}, 39 \mathrm{~h}$ \\
&
\end{tabular}

\section{2}

\section{Historical Background}

Soluble AuNPs appeared about two thousand years ago and were used as pigments for esthetic and curative purposes. On the materials side, their use to make ruby glass and for coloring ceramics was known in these ancient times, as exemplified by the famous Lycurgus cup (dated 4th century AD, British Museum) [8a]. Modern syntheses of NPs are often inspired by the 150-year old method of Faraday who demonstrated the formation of red solutions of AuNPs by reduction of tetrachloroaurate $\left[\mathrm{AuCl}_{4}\right]^{-}$using phosphorus as the reducing agent [8a,b]. This strategy has been popularized again by Schiffrin's group in 1993 [8a,c], using $\mathrm{NaBH}_{4}$ reduction of a metal precursor such as $\mathrm{HAuCl}_{4}$ in a biphasic organic solvent-water system in the presence of the phase-transfer reagent $\left[\mathrm{N}\left(\mathrm{C}_{8} \mathrm{H}_{17}\right)_{4}\right] \mathrm{Br}$ followed by the addition of a thiol that stabilizes the NPs as a thiolate ligand [8a,c]. Likewise, 


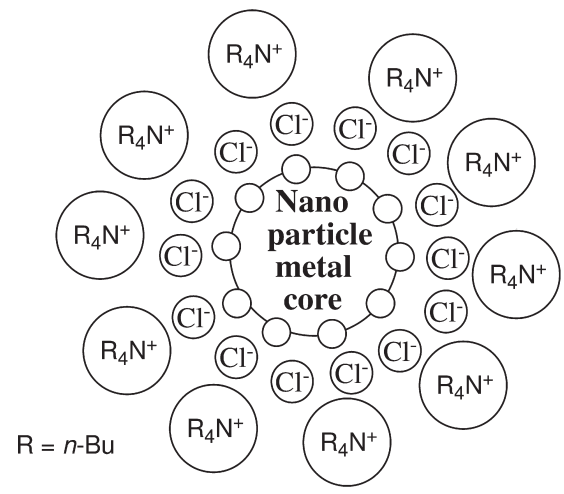

Fig. 1.1 "Electrosteric" (i.e. electrostatic with the halide anions located between the positively charged NP surface and the tetra- $N$ butyl ammonium cations and steric with the tetra- $N$-butyl ammonium cation) stabilization of metal NPs obtained by reduction of a metal chloride salt in the presence of a tetra- $N$-butyl ammonium cation (Bönnemann-type synthesis of Eq. (1.1)). The presence of chloride or other anions (rather than ammonium cations) near the NP surface was demonstrated. Finke showed that the order of stabilization of IrNPs by anions followed the trend: polyoxometallate $>$ citrate $>$ polyacrylate $\sim$ chloride. Thus, the stabilization of metal NPs by anions can also have an important steric component $[25 f, g]$.

Caruso reported the synthesis and stabilization of PdNPs using $\mathrm{Na}_{2} \mathrm{PdCl}_{4}$ and (4dimethylamino)pyridine [8d]. Since the 1980 s, metal salts, a molecular stabilizer and a reductant $[4-7,11]$ have been used by Bönnemann, as represented in Eq. (1.1) [6].

\section{THF}

$$
\begin{aligned}
& \mathrm{MX}_{n}\left(\mathrm{NR}_{4}\right)_{m}+(n-m) \operatorname{Red} \rightarrow \mathrm{M}_{\mathrm{NP}}+(n-m)\left(\operatorname{Red}^{+} \mathrm{X}^{-}\right)+m\left(\mathrm{NR}_{4}{ }^{+} \mathrm{X}^{-}\right) \\
& \mathrm{M}=\text { Group 8-10 metal, } \mathrm{X}=\mathrm{Cl} \text { or Br, } \mathrm{R}=\mathrm{C}_{4-12} \text { alkyl, } \\
& \quad \text { Red }=\mathrm{M}^{\prime} \mathrm{H}\left(\mathrm{M}^{\prime}=\mathrm{H}, \mathrm{Li}, \mathrm{LiBEt}_{3}, \mathrm{NaBEt}_{3}, \mathrm{KBEt}_{3}\right) .
\end{aligned}
$$

In Chapter 2, Helmut Bönnemann, Kyatanahalli S. Nagabhushana and R. M. Richards review these pioneering studies as well as recent advances in catalysis with both homogeneous and heterogeneous reactions. Typical successful catalytic reactions include the hydrogenation of $C=C, C=O$ and $C=N$ bonds, the reduction of $N-O$ bonds and the formation of $C-C$ bonds (typically Suzuki). The use by Bönnemann's group of metal NPs as electrocatalysts (i.e. the catalysis of anodic oxidation or cathodic reduction reactions, essentially methanol and CO oxidation) is also addressed, and this concept is widely applied to the design of fuel cells whereby the combination of two or several metals provides a positive synergy for catalytic activation.

Another early popular NP synthetic method used the thermal decomposition of metal( 0 ) precursors in the form of, for instance, metal carbonyls (Fe, Co, $\mathrm{Ni}, \mathrm{Ru}$, $\mathrm{Rh}, \mathrm{Ir})$ in the presence of stabilizing polymers [8e-g]. This method was not only useful for catalytic purposes, but in 1996 Hess and Parker [8h] and Thomas [8i] also reported in on the ferromagnetic properties (ferrofluids) and used the thermal 
decomposition of dicobaltoctacarbonyl as a versatile method. Other zero-valent metal complexes such as $\mathrm{Pd}(\mathrm{dba})_{2}$ and $\mathrm{M}_{2}(\mathrm{dba})_{3}(\mathrm{M}=\mathrm{Pd}, \mathrm{Pt})$ were reported in 1970 by Takahashi et al., then, in 1991, the Gallezot group produced efficient NP catalysts upon reaction with either $\mathrm{H}_{2}$ or $\mathrm{CO}$. The Bradley-Chaudret group reported the hydrogenation of zerovalent complexes of olefinic ligands as early as 1992 [8j]. The metal-vapor technique to produce metal NPs, conceptually (but not practically) an ideal one, was first published in 1927 by Roginski and Schalnikoff [81] and was made popular in modern times by work from the groups of M. L. H. Green, Timms and Ozin $[8 \mathrm{~m}]$. Physical synthetic means $[6-8,10,11]$ such as electrochemistry, developed by Reetz [7], became numerous in the 1980s for the synthesis of transition-metal NPs that were subsequently used in catalysis.

Considering now catalysis with NPs that are directly connected to the NP surfaces, Oswald's papers in 1907 that focused on the dramatic increase of NP surface when a given cube was divided into small cubes were especially seminal. A useful pioneering review on early transition-metal NP synthesis and catalysis has been published by John S. Bradley in the book on colloids and clusters edited by G. Schmid in 1994 [5d].

It has been well known since the nineteenth century that photography involves AgNPs whereas the decomposition of hydrogen peroxide was carried out by Bredig in 1899 using PtNPs [5d]. Catalytic studies using transition-metal NP catalysts became popular in the second half of the twentieth century with a small but important group of reactions, namely hydrogenation, hydrosilylation and hydration of unsaturated organic substrates and redox reactions including water photosplitting and photocatalytic hydrogenation. Thus, pioneering catalytic applications of NPs were reported in 1940 by Nord on nitrobenzene reduction [9a], in 1970 by Parravano on hydrogen atom transfer between benzene and cyclohexane and oxygen atom transfer between $\mathrm{CO}$ and $\mathrm{CO}_{2}$ using AuNPs [9b]. Then, Haruta's seminal and famous studies on oxide supported AuNP-catalyzed CO oxidation by $\mathrm{O}_{2}$ at low temperatures were a real breakthrough, resulting from his understanding that it was small, oxide-supported AuNPs that were active and that the nm-size was crucial (see Chapter 15 and [9c-e]). In the 1970s, Bond and Sermon [9f] and Hirai et al. [9g] disclosed AuNP-catalyzed olefin hydrogenation. Hirai's contribution in the 1970s and 1980s was especially impressive with the use of RhNPs that were generated using aqueous methanol or $\mathrm{NaOH}$ in methanol as a reducing agent for $\mathrm{RhCl}_{3} \cdot 3 \mathrm{H}_{2} \mathrm{O}$, producing PVA-stabilized RhNPs that were more active than previously reported RhNPs/PVA due to NP size reduction to one or only a few $\mathrm{nm}[9 \mathrm{~g}]$. The Maire group showed the efficiency of micelles for the NP catalytic hydrogenation of unsaturated substrates in the early 1980s [9h]. The preparation of NP in constrained environments including microemulsions, micelles, inverse micelles and vesicles was pioneered by the seminal work from the group of Fendler in the early 1980s [9i]. On these lines, Hirai collaborated with Toshima in the 1980s in work involving the use of various surfactants to stabilize catalytically active PtNPs produced by reduction of $\mathrm{H}_{2} \mathrm{PtCl}_{6}$, either photochemically or by reaction with dihydrogen. Toshima actively pursued his research on metal NPs in catalysis in the early 1990s with polymer-stabilized well-mixed bimetallic NPs 
generated either by direct co-reduction of two salts of two different metals (such as Pt and Au), by sequential reduction (the first reduced NPs serving as seeds for the surface condensation of the second metal) or by galvanometric reduction of a metal salt by initially produced NPs of another more easily reduced metal [5f,g]. In 1986, another well-known work appeared by Lewis who demonstrated the colloidal mechanism of olefin hydrosilylation catalysis by silanes using organometallic complexes of Co, Ni, Pd or Pt including Speier catalyst (alcoholic $\mathrm{H}_{2} \mathrm{PtCl}_{6}$ ) [9j], whereas these catalysts were formerly believed to follow the classic monometallic organometallic mechanism (i.e. oxidative addition of the $\mathrm{Si}-\mathrm{H}$ bond of the silane to the transition-metal center, followed by alkene insertion and reductive elimination). That decade saw the beginning of extended NP catalytic studies, especially in the fields of redox catalysis, photocatalysis (photo-water splitting and photohydrogenation of alkenes, alkynes and $\mathrm{CO}_{2}$ ) [10a-g], hydrogenation of unsaturated substrates and oxidation [10h,i]. NPs synthesized as indicated above using the Bönnemann-type synthesis from metal salts were further used in various hydrogenation reactions and $\mathrm{C}-\mathrm{C}$ coupling reactions such as the Heck reactions between butyl acrylate and iodobenzene or aryl bromides and styrene [4, 5, 7, $11]$.

The first years of this twentyfirst century have seen an exponential number of publications in the NP field with goals of both (i) improving catalyst activities and selectivities and (ii) understanding the catalytic mechanisms [11]. The modes of preparation of catalytically active NPs have been diverse and currently include impregnation [12a], co-precipitation [12a,b], deposition-precipitation [12c], sol-gel [12a,d], gas-phase organometallic deposition [12f], sonochemical [12g], microemulsion [12h], laser ablation [12i], electrochemical [12j], and cross-linking [12k]. We will classify and discuss the categories of NP catalysts by the type of support, and then the various reactions will be collected by references in Table 1.1. The field of metal NP catalysis is now spreading in several directions around the interface between homogeneous catalysis and heterogeneous catalysis with mutual benefits.

\section{3}

\section{Polymers as NP Stabilizers}

Polymers provide metal NP stabilization not only because of the steric bulk of their framework, but also by weak binding to the NP surface by the heteroatom, playing the role of ligands. Poly(N-vinyl-2-pyrrolidone) (PVP) is the most commonly used polymer for NP stabilization and catalysis, because it fulfils both steric and ligand requirements [5f]. For instance Pt-, Pd- and RhNPs stabilized by PVP, are synthesized by refluxing ethanolic reduction of the corresponding metal halide and immobilized in an ionic liquid, 1- $n$-butyl-3-methylimidazolium hexafluorophosphate $\left([\mathrm{BMI}]\left[\mathrm{PF}_{6}\right]\right)$, and are very efficient olefin and benzene hydrogenation catalysts at $40^{\circ} \mathrm{C}$ that can be recycled without loss of activity (see Chart 1.1 for the two major polymer formulas used for NP catalysis) [12k]. 




PVP



PPO

poly(vinylpyrrolidone)

poly(2,5-dime thylphenylene oxide)

Chart 1.1 Two major polymer families used as metal NP supports for catalysis


EtOAc, $23^{\circ} \mathrm{C}, 5 \mathrm{~h}$

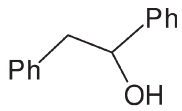

$99 \%$ isolated yield catalyst recycled 10 times

Scheme 1.1 Ring-opening hydrogenolysis of epoxides catalyzed by PdNPs $(2 \mathrm{~nm})$ microencapsulated in polyurea. Recycling experiments can be carried out at least ten times with $97-99 \%$ yield. (Ref. [14a], Yu group, Org. Lett. 2003, 4665).

With standard PVP-stabilized NP catalysts, parameters such as size and stability during the catalytic process have been examined. For instance, decreasing the PdNP size down to $3 \mathrm{~nm}$ in the Suzuki reaction improved the catalytic activity, suggesting that the low-coordination number vertex and edge atoms on the particle surface are active catalytic sites [13]. Many other polymers have been used recently for efficient catalysis: polyurea (Scheme 1.1) [14a], polyacrylonitrile and /or polyacrylic acid (Fig. 1.2) [14b], multilayer polyelectrolyte films (Fig. 1.3) [14c], polysilane shell-cross-linked micelles (Fig. 1.4) [14d], polysiloxane (Fig. 1.5) [14e], oligosaccharides [14f], copolymers synthesized by aqueous reversible additionfragmentation chain-transfer polymerization[14g], $\pi$-conjugated conducting polypyrrole [14h], poly(4-vinylpyridine) [14h], poly(N,N-dialkylcarbodiimide[14i], polyethylene glycol [14j], chitosan [14k] and hyperbranched aromatic polyamides (aramids) [14l]. Classic surfactants such as sodium dodecylsulfate (SDS) are also used as NP stabilizers for catalysis [14m]. Water-soluble polymers have been used with success for selective hydrogenation of cyclic vs. non-cyclic olefins [5d].

A very important concept pioneered in the 1970s is that of catalysis using two different metals such as Au and Pd in the same NP [15]. This idea has been beautifully developed by Toshima's group who used PVP to stabilize core-shell bimetallic Au-PdNPs, i.e. for instance NPs in which the core is Au whereas Pd atoms are located on the shell (Fig. 1.6) [16]. Subsequent to co-reduction, this structure is controlled by the order of reduction potentials of both ions and the coordination abilities of both atoms to PVP. The location of Au in the core and Pd on the shell was demonstrated by EXAFS, and it was shown that such heterobimetallic 



Fig. 1.2 PdNP adsorbed on polyacrylic acid particles as hydrogenation catalyst: stabilizing effect of a PdNP due to adsorbed block copolymer (Reprinted with permission from Ref. [14c]; Gröschel group, Catal. Lett. 2004, 95, 67).
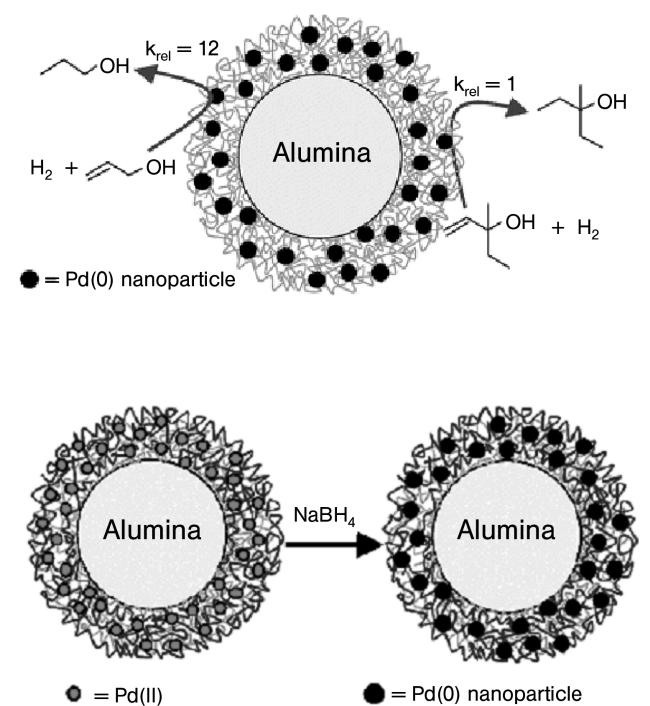

Fig. 1.3 Principle of the formation of PdNPs in multilayer polyelectrolyte films for selective hydrogenation (the layer-bylayer deposition is both convenient and versatile) (Reprinted with permission from Ref. [14d]; Bruenning group, J. Am.

Chem. Soc. 2004, 126, 2658). 


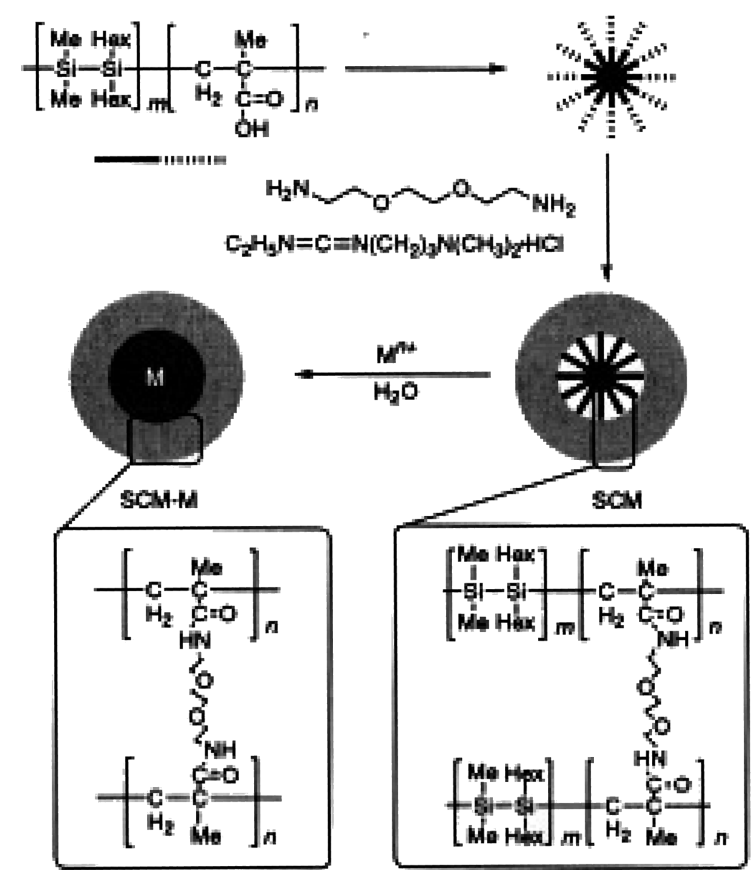

Fig. 1.4 Schematic illustration of the synthesis of metal NPs derived from polysilane shell cross-linked micelle templates (Reprinted with permission from Ref. [14f]; Sakurai group, Chem. Lett. 2003, 32, 980).

Au-cored PdNPs are more active in catalysis than simple PVP-stabilized PdNPs. Thus, the Au core enhances the catalytic properties of PdNPs at the PdNP surface [5f,g]. Conversely, design strategies can lead to the opposite core-shell structure (Pd core, Au shell), and specific catalytic properties were obtained for methylacrylate hydrogenation [16].

Cyclohexene hydrogenation was catalyzed with PdNPs stabilized by highly branched amphiphilic polyglycerol (75\% esterified with palmitoyl chloride) and this system was submitted to a continuously operating membrane reactor for recovery and recycling of the PdNP catalyst [16c].

In Chapter 3, Lyudmila M. Bronstein, Valentina G. Matveeva and Esther M. Sulman review metal NP catalysis using polymers, in particular, work in Bronstein's group concerning the hydrogenation of chain acetylene alcohols and direct oxidation of L-sorbose. These authors stress the importance of and interest in block copolymers such as polystyrene-block-poly-4-vinylpyridine, PS-b-4VP, and even better poly(ethylene oxide)block-poly-2-vinylpyridine, PEO-b-P4VP (the latter being used in water). The catalytic efficiency is optimal for the smallest NPs and decrease as the NP size decreases. 
(a)

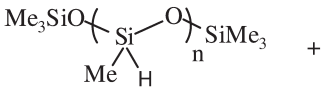
1 :<smiles>C=Cc1ccccc1</smiles>

0.5

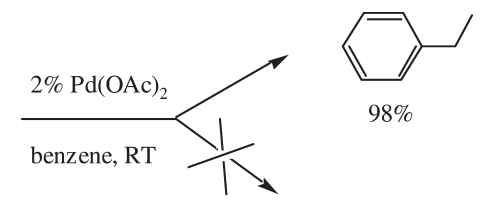

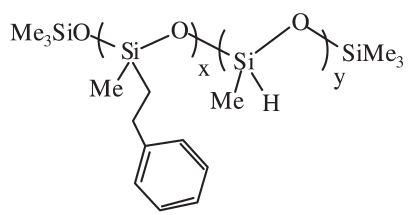

(b)<smiles>CS(=O)(=O)O[Si]([14CH3])([14CH3])O[Na]</smiles>

$\mathrm{n}=33-35$

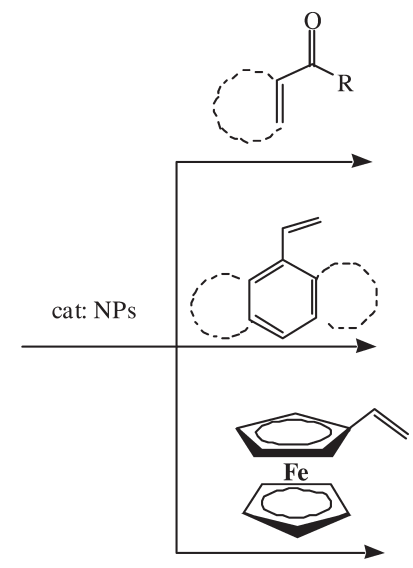<smiles>C=Cc1c2c(cc3c1CCC3)CCCC2</smiles>

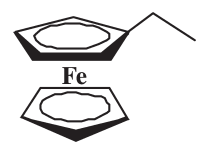

Fig. 1.5 Polysiloxane-PdNPs, generated by reduction of $\mathrm{Pd}(\mathrm{OAc})_{2}$ with polymethylhydrosiloxane, as recyclable chemoselective hydrogenation catalysts: selective reduction of styrene (a) and polysiloxane-PdNP catalyzed reduction of alkenes (b). (Ref. [14e]; Caudhan group, J. Am. Chem. Soc. 2004, 126, 8493).

\section{4}

\section{Dendrimers as NP Stabilizers}

Dendrimers are hyperbranched macromolecules that are constructed around a core and are well defined by regular branching generation after generation. Dendrimers, as polymers, are macromolecules; but unlike polymers, they are perfectly defined on the molecular level with a polydispersity of 1.0 [17]. Having shapes of molecular trees or cauliflowers, they become globular beyond low generations, and thus behave as molecular boxes [17c] that can entrap and stabilize metal NPs, especially if they contain heteroatoms in their interiors [17d,18]. The dendritic branches and termini can serve as gates to control access of small substrates inside the dendrimer to the encapsulated NP. Finally, the dendrimer terminal groups 
a) Particle-in-particle

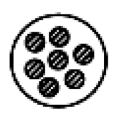

d) Core-shell particle

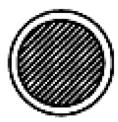

b) Particle-on-particle



e) Alloy particle

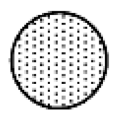

c) Aggregated particle

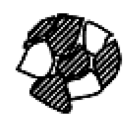

f) Separate particle

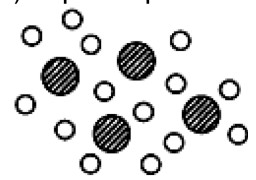

g) Super core-shell particle



Metal A

Metal B

AB Alloy

Fig. 1.6 Summary of representative morphologies of bimetallic nanoparticles (Reprinted with permission from ref. 16a, Kunitake and Toshima groups, J. Am. Chem. Soc. 2003, $125,11034)$.

provide the desired solubility in organic, aqueous or fluorous media. The formation of NPs stabilized by dendrimers was proposed in 1998 by three research groups Crooks [11b,18a], Tomalia [19a,b] and Esumi [19c-e]. The first two groups introduced the metal NPs inside the dendrimers whereas the last one stabilized them at the dendrimer periphery. The former strategy has proved very successful because of the molecular definition of dendrimers that encapsulate NPs and their ability to serve as a box and generation-dependent filter of substrates. Crooks [18a] showed that complexation of the inner nitrogen atoms of tertiary amines by metal cations $\left(\mathrm{Cu}^{2+}, \mathrm{Au}^{3+}, \mathrm{Pt}^{2+}, \mathrm{Pd}^{2+}, \mathrm{Fe}^{3+} \mathrm{Ru}^{3+}\right)$ could be followed by reduction by $\mathrm{NaBH}_{4}$ to metal(0) leading to the agglomeration of metal atoms to NPs inside the PAMAM dendrimers. Crooks also pioneered the field of catalysis using these dendrimerencapsulated nanoparticles (DENs), and some examples of the work of his research group follow [18a]. When the terminal amino groups were protonated at $\mathrm{pH} 2$ prior to complexation by metal ions, the latter proceeded selectively onto the inner nitrogen atoms, resulting in water solubility and subsequent catalytic activity in water. For instance, selective hydrogenation of allylic alcohol and $\mathrm{N}$-isopropyl acrylamide was catalyzed in water by such PAMAM dendrimer-PdNPs (Fig. 1.7 and Chart 1.2). The addition of decanoic acid solubilizes the dendrimer-NP catalyst in toluene by terminal amino group-carboxylic acid reaction, and the catalyst hydrogenates the substrates more rapidly than in water. Alternatively, a perfluorinated polyether "ponytail" can be covalently grafted in order to solubilize the PAMAM-dendrimer PdNP catalyst in supercritical $\mathrm{CO}_{2}$, and this catalyst was shown to perform classic Pd-catalyzed Heck coupling between aryl halides and methacrylate, yielding predominantly (97\%) trans-cinnamaldehyde. Oxidation 


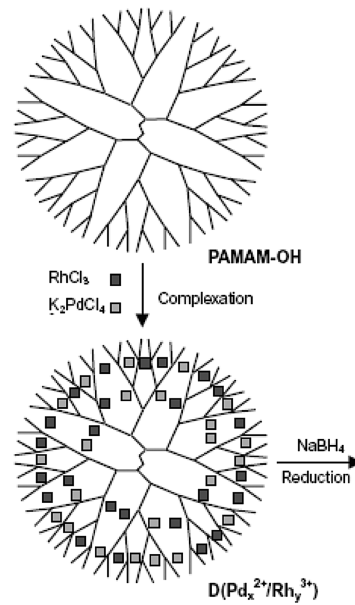

Fig. 1.7 Strategy pioneered by Crooks for the catalysis by NPs encapsulated in PAMAM or PPI dendrimers: complexation of the inner nitrogen atoms of tertiary amines by a metal cation, then reduction to metal(0) by $\mathrm{NaBH}_{4}$ leading to the formation of NPs inside the dendrimer, followed by the catalyzed reaction. The use of PIP dendrimers requires control of the $\mathrm{pH}$ before metal ion complexation in order to selectively protonate the terminal amino group ( $\left.\mathrm{p} K_{\mathrm{a}}=9.5\right)$, not the inner ones $\left(\mathrm{p} K_{\mathrm{a}}=5.5\right)$ whereas in the PAMAM series, $\mathrm{OH}$-terminated dendrimers are used (Ref. [18f]; Crooks, Acc. Chem. Res. 2001, 34, 181). Schematic diagram for the preparation of dendrimer-encapsulated bimetallic NPs (Reprinted with permission from Ref. [23]; Rhee group, J. Mol. Catal. A: Chem. 2003, 206, 291).

[18a] and reduction [18b] catalysis could be achieved using such dendrimerencapsulated NPs. Crooks' work on homogeneous catalysis using DENs is also detailed in the first part of Chapter 4 by Bert Chandler and John D. Gilbertson that is also devoted to heterogeneous catalysis using DEN precursors [20] (vide infra).

El Sayed investigated in details the effect of the PAMAM dendritic generation on the catalytic activity in the Suzuki $\mathrm{C}-\mathrm{C}$ coupling reaction between phenyl iodide and phenylboronic acid at $80^{\circ} \mathrm{C}$. Generations 3 and 4 were found to be good stabilizers (contrary to generation 2), because the dendrimers stabilize the metal NPs by preventing their agglomeration but they do not fully passivate the metal surface. The PAMAM dendrimer-stabilized PdNPs $(1.3 \pm 0.1 \mathrm{~nm})$ were compared to PVP-stabilized PdNPs $(2.1 \pm 0.1 \mathrm{~nm})$ for this Suzuki reaction carried out in $3: 1$ $\mathrm{MeCN}: \mathrm{H}_{2} \mathrm{O}$ at $100^{\circ} \mathrm{C}$, and the mechanism was found to be similar with phenylboronic acid adsorption onto the NPs, but the 2 nd cycle/1st cycle ratio was higher for the dendrimer-PdNP catalyst [11a, 21]. Using a different mode of synthesis of these 4th-generation PAMAM dendrimer-stabilized PdNPs $(3.2 \pm 1 \mathrm{~nm})$ as catalysts, Christensen found Suzuki coupling to occur with iodobenzene in $\mathrm{EtOH}$ at $78^{\circ} \mathrm{C}$, whereas bromobenzene requires a temperature of $153^{\circ} \mathrm{C}$ in DMF. The amount of catalyst was only $0.055 \%$, which is significantly less than with traditional catalysts. It was suggested that, since the G4-dendrimer diameter is only $4.5 \mathrm{~nm}$, the PdNPs are stabilized by the dendrimer rather than encapsulated [22a]. In studies with 3rd- to 5th-generation poly(propylene imine) (PPI) functionalized 


<smiles>NCCCN(CCN)CCCN(CCCN(CCCN)CCCN)CCCN(CCCN(CCCN)CCCN)CCCN(CCCN)CCCN</smiles>

\section{G1 PPI Dendrimer}

Chart 1.2 The two families of commercial dendrimers considered as metal NP support for catalysis: PAMAM and $\mathrm{PPI}$ dendrimers (only the first generation $\mathrm{G} 1$ is represented). PPI dendrimers are smaller then PAMAM $(2.8 \mathrm{~nm}$ vs. $4.5 \mathrm{~nm}$ for $\mathrm{G} 4$, respectively), but more stable $\left(470^{\circ} \mathrm{C}\right.$ vs. $100^{\circ} \mathrm{C}$ respectively) [11b].

by reaction with triethoxybenzoic acid chloride, the dendrimer-stabilized PdNP catalyst led to substrate specificity for the hydrogenation of polar olefins, due to the strong interaction between polar substrates and the inner tertiary amino groups. For instance, in competitive hydrogenations of 3-cyclohexene-1-methanol and cyclohexene, G5-PdNPs gave only reduction of the former while the traditional $\mathrm{Pd} / \mathrm{C}$ catalyst gave incomplete hydrogenation of both compounds under the same conditions (Fig. 1.8) [22b,c]. Catalytic activity has been found for the Heck reaction of iodobenzene with ethylacrylate in refluxing toluene (75\% yield) and Suzuki reactions of iodo- and bromobenzene with $\mathrm{PhB}(\mathrm{OH})_{2}$ in refluxing ethanol $(42-47 \%$ yield) have been observed for PdNP-cored dendrimers of the third generation. However, no activity was obtained for hydrogenation reactions [22d]. 

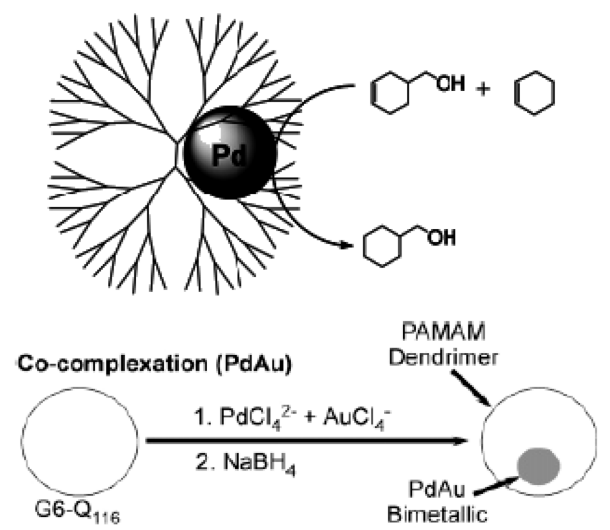

Sequential Loading [Au](Pd)



Fig. 1.8 Modes of synthesis of PAMAM-dendrimerencapsulated heterobimetallic Pd-AuNPs (Reprinted with permission from Ref. [18k]; Crooks group, J. Am. Chem. Soc. 2004, 126, 15583)

This encapsulation strategy has recently been extended to bimetallic NP catalysts $[22,23]$, evidence that these NPs are bimetallic being provided by single-particle X-ray dispersive spectroscopy (EDS) [17a,b]. It was shown that the G4-PAMAM $\mathrm{Pd} / \mathrm{M}$ NPs (M = Pt or Au) catalyze allylic alcohol hydrogenation more efficiently than the analogous monometallic Pt or Pd catalyst or their mixture, due to favorable synergistic effects [18]. When the inner PdNP was located at the dendritic core of G3-NPs, Heck and Suzuki coupling could be obtained in 38\% to $90 \%$ yield in refluxing toluene or ethanol for a day [20] (Fig. 1.9). Suzuki catalysis in PPI dendrimer-supported PdNPs was also carried out for comparison with PAMAM dendrimers $[18 \mathrm{c}]$. The form of the NPs within the dendrimer is not clear despite TEM studies. Are the NPs really completely inside the dendrimer? Is the dendritic core encapsulated in the NP? Are there several close NPs in the dendrimer cavities or are they connected? Likewise, more work is called for in order to understand the very nature of the catalytically active Pd species.

The other dendrimer stabilizing strategy carried out by Esumi involves coordination of the NPs by surface amino groups of PAMAM and PPI dendrimers [19c-e], and these catalysts were used for various catalytic reactions including the reduction of 4-nitrophenol. In this case, one may visualize PdNPs surrounded by a number 
a

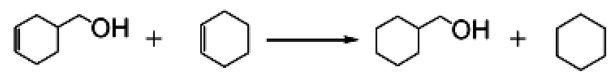

$\mathrm{Pd} / \mathrm{C}$

$60 \%$

$10 \%$

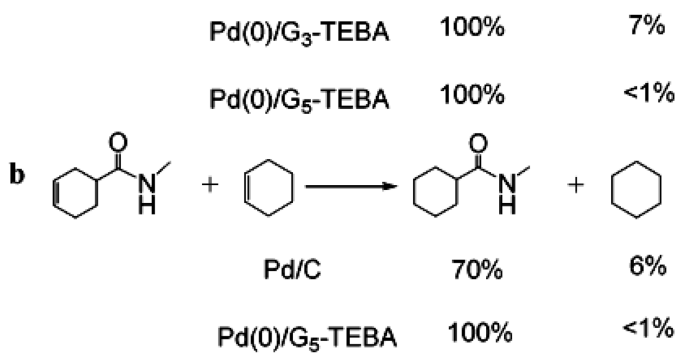

Fig. 1.9 Competitive hydrogenation of (a) 3-cyclohexene-1methanol and cyclohexene (b) N-methyl-3-cyclohexene-1carboxamide and cyclohexene using various Pd catalysts (Reprinted with permission from Ref. [22b], Kaneda group, Nano Lett. 2002, 2, 999).

of dendrimers that can also bridge PdNPs. In both situations, the dendrimers clearly stabilize small nanoparticles by a combination of polyligand and steric effects. Whether these dendrimer-stabilized PdNPs are the active species in Pd catalysis or reservoirs of much smaller, very active, Pd fragments, is unclear.

In Chapter 4, Bert Chandler and John D. Gilbertson also review, in addition to homogeneous DEN catalysis, their use of dendrimer-protected NPs heterogeneous systems. Indeed, Chandler's group has grafted DENs (including bimetallic ones) onto a variety of solid supports and used the resulting solids as heterogeneous catalysts, for instance for $\mathrm{CO}$ oxidation. The dendrimer protection of these NPs is removed at high temperature $\left(150^{\circ} \mathrm{C}\right.$ to $\left.300^{\circ} \mathrm{C}\right)$, the PAMAM dendrimers being thermally unstable.

\section{5}

\section{Ligand Stabilization of NPs}

The introduction of ligands as NP stabilizers is of special interest, because it focuses on the precise molecular definition of the catalytic materials. In principle, this strategy potentially allows a good control of the molecular modulation in order to optimize the parameters that govern the efficiency in catalytic reactions, including enantioselective ones.

Gladysz showed that a thermomorphic fluorous palladacycle acts as a PdNP catalyst precursor for the Heck reaction at $80-140^{\circ} \mathrm{C}$ in DMF with very high turnover numbers [24a]. Molecular palladium complexes such as palladacycles and other palladium salts have also been used as PdNP precursors upon treatment with CO in DMF or toluene at room temperature, and these PdNPs catalyzed nucleophilic substitution/carbonylation/amination affording iso-indolinones at room temperature [24b]. PdNPs capped with special ligands such as polyoxometal- 
lates [25] and cyclodextrins [26] were shown to be active for the catalysis of the hydrogenation of unsaturated substrates and of the Suzuki, Heck and Stille reactions. For instance, iodo- and bromoarenes and iodoferrocene are coupled to phenyl boronic acid by refluxing in $\mathrm{MeCN}: \mathrm{H}_{2} \mathrm{O}, 1: 1(\mathrm{v} / \mathrm{v})$ in the presence of $\mathrm{K}_{2} \mathrm{CO}_{3}$ or $\mathrm{Ba}(\mathrm{OH})_{2}$ and $1 \%$ perthiolated $\beta$-cyclodextrin-PdNPs [26a]. These 3-nm PdNPs are also active for the hydrogenation of water-soluble alkenes [26b,c]. In fact, the simplest dodecathiolate-PdNPs catalyze the Suzuki reaction of halogenoarenes, including chloroarenes, with phenylboronic acid, even at ambient temperature, and recycling several times has been achieved [27]. Another very simple mode of stabilization involved addition of silanes $\mathrm{R}_{3} \mathrm{SiH}$ such as tert-butyldimethylsilane to $\mathrm{PdX}_{2}\left(\mathrm{X}=\mathrm{Cl}^{-}, \mathrm{OAc}^{-}\right)$in $N, N$-dimethylacetamide. The black NP solution formed in this way catalyzed silane alcoholysis of sugars [28a] and selective cross-coupling of the silane with phenyl and vinyl thioethers giving the corresponding thiosilanes and silthianes (Eq. (1.2)) [28b]:

$$
\mathrm{RSR}^{\prime}+\mathrm{HSi}(t-\mathrm{Bu}) \mathrm{Me}_{2} \stackrel{\text { PdNPs }}{\underset{\mathrm{DMA}}{\rightarrow}} \mathrm{HSi}(t-\mathrm{Bu}) \mathrm{Me}_{2}+\mathrm{R}^{\prime} \mathrm{H} \quad \text { at } 25^{\circ} \mathrm{C}
$$

$\mathrm{R}$ and $\mathrm{R}^{\prime}=$ alkyl, aryl; $\mathrm{DMA}=N, N^{\prime}$-dimethylacetamide

In view of atom economy, the synthesis of core-shell NPs having a cheap metal core such as Ni and a noble metal shell such as Pd has been achieved by thermal decomposition $\left(235^{\circ} \mathrm{C}\right)$ of $\mathrm{Pd}$ and Ni precursors $\left(\left[\mathrm{Ni}(\mathrm{acac})_{2}\right]+\left[\mathrm{Pd}(\mathrm{acac})_{2}\right]+\right.$ trioctylphosphine), the Ni complex decomposing before the Pd one. The Ni-cored PdNPs showed a much better activity than PdNPs without Ni, and having the same amount of $\mathrm{Pd}$ atoms, for the Sonogashira coupling of $p$-bromoacetophenone with phenylacetylene in toluene at $80^{\circ} \mathrm{C}$, although $p$-chloroacetophenone was unreactive [28c]. Enantioselective reactions have been carried out with metal NPs $[29,30]$. The first example of an asymmetric reaction catalyzed by metal NPs was reported by the group of Lemaire, Besson and Gallezot in 1994 with the RhNP catalyzed hydrogenation of 2-methylanisole $o$-cresol trimethylsilyl ether induced by a chiral amine, R-dioctylcyclohexyl-1-ethylamine as a RhNP ligand [29]. The hydrogenation of ethyl pyruvate was found by Bönnemann [30a] to be efficiently catalyzed by cinchonidine-Pt- or PdNPs (75-80\% ee, Scheme 1.2), and the ee was later improved (up to 95-98\%) [30b-d]. Fujihara reported 2,2'-bis-(diphenylphosphino)-1,1'-binaphtyl [BINAP] - stabilized PdNPs with a diameter of $2.0 \pm$ $0.5 \mathrm{~nm}$ and narrow size distribution. It was found that these BINAP-PdNPs catalyzed asymmetric hydrosilylation of styrene under mild conditions (ee: 95\% at $0^{\circ} \mathrm{C}$ ), in contrast to inactive monometallic BINAP-Pd complexes [30e]. Recently, enantioselective allylic alkylation was reported by the Gomez and Chaudret groups to be catalyzed by PdNPs stabilized by a chiral xylofuranide diphosphite with $97 \%$ ee [30f]. The authors of these few NP reports support catalysis by the NP themselves. The very nature of the catalytically active species (and also whether catalysis actually occurs on the NP surface) remains unclear, however, and the catalytically active species may equally well be much smaller Pd fragments, leaching from the 

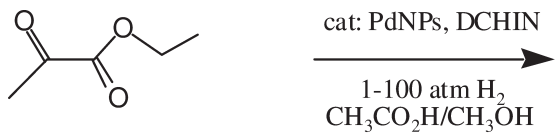

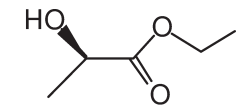

ee $=75-80 \%$

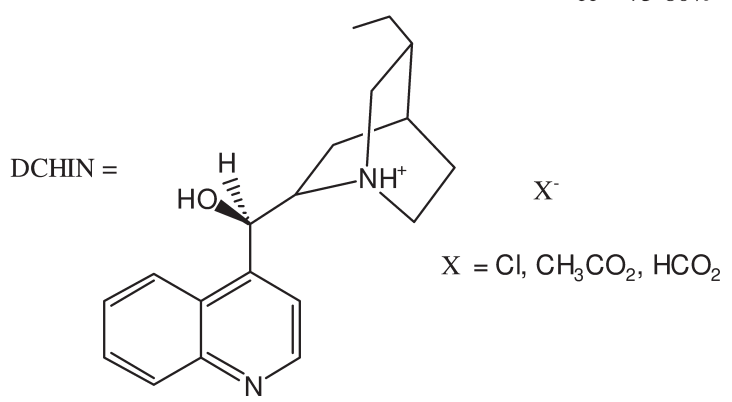

Scheme 1.2 Enantioselective hydrogenation of ethyl pyruvate catalyzed by cinchonidine-Pt- or PdNPs (Ref. [30a], Bönnemann group, Chem. Eur. J. 1997, 2, 1200).

NP, to which the asymmetric ligand is bound. Anyway, the selectivity obtained is remarkable.

\section{6}

\section{"Ligand-free" Heck Reactions using Low Pd-Loading}

The original reports by Mizoroki [31a], then by Heck [31b], on the Pd-catalyzed coupling reaction of aryl iodides with olefin used a $\mathrm{Pd}$ salt $\left(\mathrm{PdCl}_{2} \operatorname{resp} . \mathrm{Pd}(\mathrm{OAc})_{2}\right)$, a base ( $\mathrm{NaOAc}$ resp. $\mathrm{NBu}_{3}$ ) and a solvent (methanol resp. $\mathrm{N}$-methylpyrolidone), but no phosphine or other ligand. Beletskaya reported a similar phosphine-free reaction of iodo- and bromoarenes in water, and the Pd-loading was as low as $0.0005 \mathrm{~mol} \%$ (the term "homeopathic dose was used) with 3-iodobenzoic acid [31c]. The Reetz [31d,n] and de Vries [31e,n] groups reported extremely efficient Heck catalysis of coupling between aryl bromides and styrene in organic solvents with such very low Pd-loading. Reetz found that PdNPs are formed when $\mathrm{PdCl}_{2}$, $\mathrm{Pd}(\mathrm{OAc})_{2}$ or $\mathrm{Pd}\left(\mathrm{NO}_{3}\right)_{2}$ is warmed in THF in the presence of a tetrabutylammonium carboxylate that functions as a reducing and stabilizing agent [31f]. Polar solvents such as propylene carbonate also generated such PdNPs upon heating $\mathrm{Pd}(\mathrm{OAc})_{2}$. PdNPs generated in this way from $\mathrm{Pd}(\mathrm{OAc})_{2}[31 \mathrm{~d}-\mathrm{f}$ ] or palladacycles [31g-i] are active catalysts in the Heck reaction, as demonstrated by following the reactions using TEM. [31j] Very interestingly, it was found that the Pd catalyst "improves" upon lowering the Pd-loading, which was accounted for by an equilibrium between PdNPs serving as a catalyst reservoir and small (monomeric or dimeric) catalytically active Pd species [31d,h,k]. When the catalyst concentration is too high, inactive Pd black forms (Scheme 1.3).

This points to the fact that the rate of the catalytic reaction must be extremely high, since most of the Pd is in the form of PdNPs. This type of Heck reaction 
<smiles>CCOC(=O)C=Cc1ccccc1</smiles>

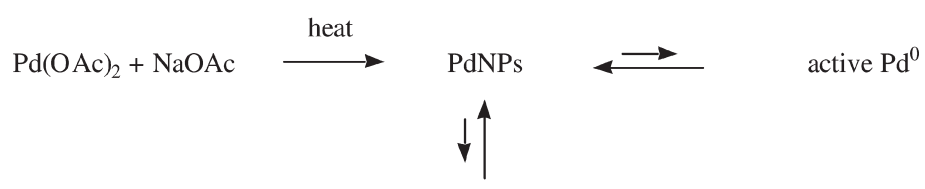

Pd black

Scheme 1.3 Heck-type reactions catalyzed by extremely low loading of Pd salt proceeding via PdNPs (Refs. [31d,f,j,n] Reetz group).

seems quite general with aryl bromides and has been scaled up by DSM to the $\mathrm{kg}$ scale in order to prepare a drug intermediate [31e]. Likewise, a range of enantiopure substituted $\mathrm{N}$-acetyl-phenylalanines was obtained from methyl $\mathrm{N}$-acetamidoacrylate and various bromoarenes at very low Pd-loading in the absence of other ligands, followed by Rh-catalyzed hydrogenation [311]. De Vries reported similar behavior for the Suzuki reaction of aryl bromides with TOFs up to 30000 [31m]. The precise nature of the active species in these Pd-catalyzed $\mathrm{C}-\mathrm{C}$ coupling reactions is not known, and it may well be an anionic mono- or dimeric $\mathrm{Pd}^{0}$ species to which an anionic ligand $\left(\mathrm{Cl}^{-}\right.$or $\left.\mathrm{OAc}^{-}\right)$is bound [32-34]. This means that the anionic Amatore-Jutand mechanism that has now met general acceptance for homogeneous Heck catalysis is also operating with many heterogeneous systems (Scheme 1.4). This type of catalysis is very important in term of "Green Chemistry" as waste is largely minimized here in the absence of added ligand and such low Pd-loading [31n]. It also suggests that supported PdNP catalysts (heterogeneous catalysts, vide infra) could well behave in a related way. The Jones group has recently published an important comprehensive review on the nature of active species in Pd-catalyzed Heck and Suzuki-Miyaura reactions [31o]. This concept could be extended to other types of catalysis, and indeed other examples of PdNP pre-catalysts are known for C-C bond formation for which Pd is the best metal catalyst [31p] (Scheme 1.5). Other metal NP catalysts are also known, for instance Pt-catalyzed hydrosilylation [5c] and Ru-catalyzed hydrogenation using transitionmetal complexes. RuNPs have also been shown to catalyze the Heck reaction [31q].

In Chapter 10, Laurent Djakovitch, Klaus Köhler and Johannes G. de Vries review the role of PdNPs as pre-catalysts for $C-C$ coupling reactions. This chapter represents a timely general review from these experts embracing both homogeneous and heterogeneous systems. Emphasis is placed on homeopathic PdNP catalysis that was rationalized and used by de Vries earlier and on the homogeneous type of catalysis with heterogeneously supported PdNP catalysts with leaching of catalytically active Pd atoms returning after their catalytic acts onto the PdNP reservoir. 


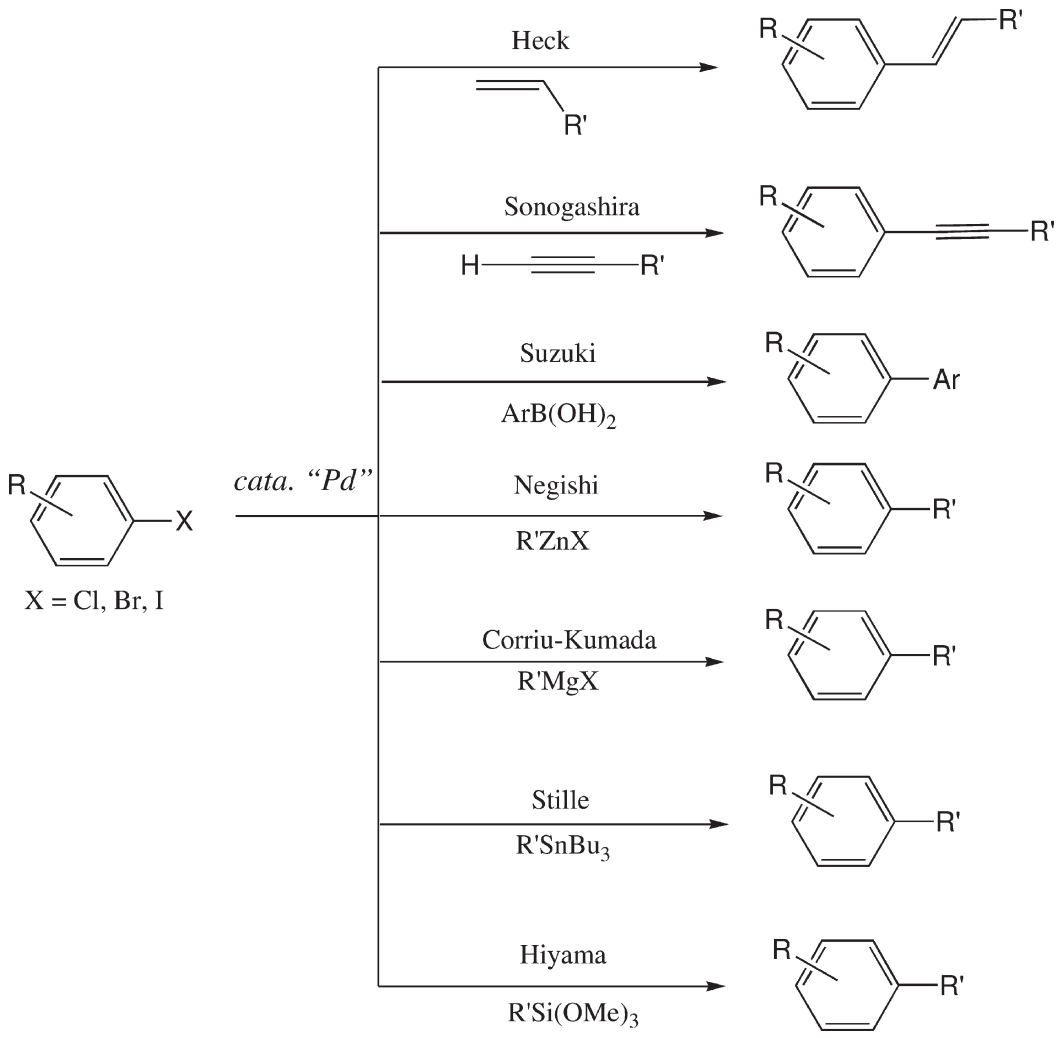

Scheme 1.4 Pd-catalyzed C-C bond formation with aryl halides and triflates.

\section{7}

The Roles of Micelles, Microemulsions, Surfactants and Aerogels

"Fluorous" strategies [32a,b] have been used on various occasions for the NP catalysis mentioned above as for instance by the Crooks [17] and Gladysz [24a] groups. Fluoro surfactants can also serve as micellar stabilizers for PdNPs in water-in- $\mathrm{ScCO}_{2}$ microemulsions that were used as hydrogenation catalysts for simple olefins [32b-d] and citral [32e]. In such systems, hydrogen can work both as a reductant for Pd salts and for the unsaturated substrate. Ultrafine PdNPs in reverse micelles using $\mathrm{KBH}_{4}$ as a reducing agent of $\mathrm{Pd}^{\mathrm{II}}$ precursors led to catalytic hydrogenation of allylic alcohol and styrene in iso-octane, although the bis(2ethylhexyl) sulfosuccinate surfactant inhibited the hydrogenation activity (Fig. 1.10) [32f]. The oxidation of $N, N, N^{\prime}, N^{\prime}$-tetramethyl-p-phenylenediamine by $\left[\mathrm{Co}\left(\mathrm{NH}_{3}\right)_{5} \mathrm{Cl}\right]^{2+}$ was catalyzed by PdNPs in an aqueous/AOT/ $n$-heptane microemulsion [32g]. Functional olefins such as 4-methoxy-cinnamic acid were selectively hydrogenated as well as nitrobenzene (to aniline) in supercritical $\mathrm{CO}_{2}$ using PdNPs in a water-in- $\mathrm{CO}_{2}$ microemulsion [32h,i]. Oxidation of cyclooctane by 
1.7 The Roles of Micelles, Microemulsions, Surfactants and Aerogels $\mid 21$

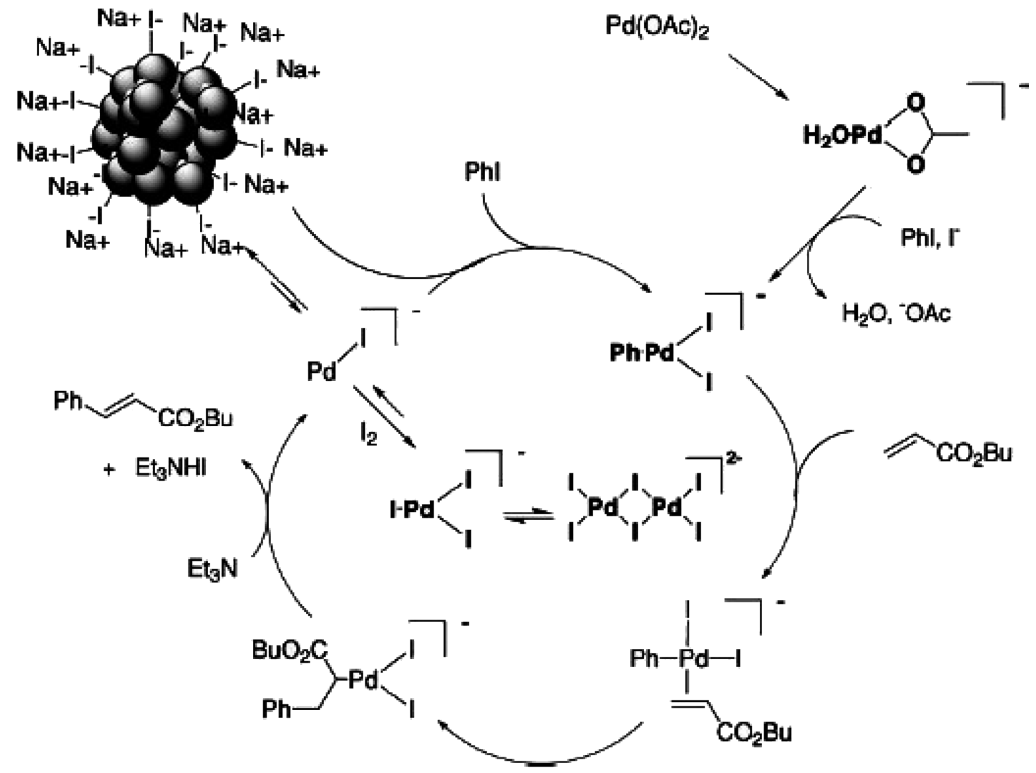

Scheme 1.5 Mechanism proposed by de Vries [31n] for the "homeopathic" Heck reaction between phenyl iodide and butyl acrylate catalyzed by $\mathrm{Pd}(\mathrm{OAc})_{2}[31 \mathrm{c}-\mathrm{f}, \mathrm{I}-\mathrm{o}]$. Reprinted with permission from Ref. [31n].


Fig. 1.10 Hydrogenation of 10-(3-propenyl) anthracene catalyzed by PdNPs in water-in-oil microemulsion (much faster than Pd/C catalysis). (Reprinted with permission from Ref. [32f]; Wai group, Chem. Commun, 2003, 1041). 

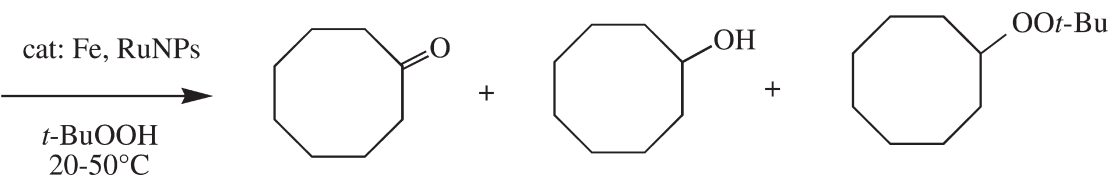

$20-50^{\circ} \mathrm{C}$

Scheme 1.6 Cyclo-octane oxidation catalyzed by FeNPs in reverse microemulsions or RuNPs in biphasic water-organic media (Ref. [49b], Roucoux-Patin group).

tert-butylhydroperoxide ( $t$ BHP) was catalyzed by FeNPs in a reverse microemulsion or with RuNPs in a biphasic water/cyclooctane solvent with recycling without loss of activity (Scheme 1.6), and microemulsions were found to be efficient in ligand-free Heck catalysis [32j].

Aerogels, less dense solid materials (with densities around $0.2 \mathrm{~g} \mathrm{~cm}^{-3}$ and high surface area around $600 \mathrm{~m}^{2} \mathrm{~g}^{-1}$ ), are excellent supports for NPs in catalysis, because they are porous and thus leave the active NP surface exposed. Aerogels are prepared by supercritical drying or liophilization of gels, and the NP-ated aerogels are prepared before, during or after the sol-gel process.

Aerogel-supported NPs in catalysis are reviewed by Adelina Vallriebera and Elies Mollins in Chapter 5. In particular, the catalysis that is reviewed in Chapter 5 with $N P$-ated arerogels includes both classic liquid-phase reactions (olefin oxidation, epoxidation and dihydroxylation, various $\mathrm{C}-\mathrm{C}$ bond formation reactions including Heck coupling, hydrocarbonylation, Claisen-Schmidt condensation, Michael addition) and high-temperature heterogeneously catalyzed processes (Fischer-Tropsch, steam reforming, CO, methanol and butane oxidation, dechlorination of chlorinated volatile organic compounds, oxygen and cyclohexene reduction by $\mathrm{H}_{2}$ and isomerizaton of 1-butene).

\section{8}

\section{Ionic Liquid Media for Catalysis by NPs}

Ionic liquids (ILs) were introduced in catalysis by Yves Chauvin in the 1990s [33a] and have received considerable attention in this field [33b,c]. Yves Chauvin introduced the imidazolium salts that are the most frequently used ILs in catalysis. ILs are valuable media for catalysis with PdNPs because the substituted imidazolium cation is bulky, favoring the electrosteric stabilization of NPs, as do the $t$ - $\mathrm{Bu}_{4} \mathrm{~N}^{+}$ salts in Fig. 1.1. The size of the cation (that can eventually be tuned by the choice of the $\mathrm{N}$-alkyl substituents) also has an important influence on the stabilization, size and solubility of the NPs, these factors playing a role in catalysis. ILs are also non-innocent, however, as they readily produce $\mathrm{Pd}-\mathrm{N}$-heterocyclic carbene complexes upon deprotonation of the imidazolium salt at sufficiently high temperature. Thus, these carbene ligands can be bound to the NP surface or give mononuclear mono- or bis-carbene complexes subsequent to leaching of Pd atoms from the PdNP surface (vide infra) [33]. 
IrNPs in 1-n-butyl-3-methylimidazolium hexafluorophosphate ([BMIM][PF 6$])$ were used directly for the hydrogenation of olefins, and good results were obtained [33b]. Phenanthroline-stabilized PdNPs prepared in [BMIM] $\left[\mathrm{PF}_{6}\right]$ according to the method reported by Schmid [33c] but without using acetic acid as the solvent, $\left(\mathrm{Pd}(\mathrm{OAc})_{2}+\right.$ Phen. $\mathrm{H}_{2} \mathrm{O}+1 \mathrm{~atm} \mathrm{H}_{2}$ in the IL at room temperature), efficiently catalyzed the hydrogenation of olefins and the selective hydrogenation of cyclohexadiene to cyclohexene under mild conditions $\left(1 \mathrm{~atm} \mathrm{H}_{2}, 40^{\circ} \mathrm{C}\right)$. Under these conditions, formation of Pd-carbene complexes from the IL does not occur, thus the IL simply plays the role of a PdNP-stabilizing solvent like other salts known to provide electrostatic NP stabilization. This catalyst could be re-used several times [33d], and it was much more active than Phen-protected PdNPs supported on $\mathrm{TiO}_{2}$ for the hydrogenation of 1-hexene [6b]. It was found that PdNPs, formed by reaction of $\mathrm{Pd}(\mathrm{OAc})_{2}$ with tetrabutylammonium acetate dissolved in tetrabutylammonium bromide, efficiently catalyzed the stereospecific reaction of cinnamates with aryl halides to give $\beta$-aryl-substituted cinnamic esters.

The role of the IL is crucial in both the PdNP formation and stereospecifity of $\mathrm{C}-\mathrm{C}$ coupling that could not be obtained in previous studies of PdNP-catalyzed Heck reactions [33e-g]. Salts of $\mathrm{N}$-butyronitrile pyridinium cation react with $\mathrm{PdCl}_{2}$ to give dinitrile complexes that turn black upon addition of phenyltributylstannane, and the PdNPs formed catalyze Stille and Suzuki C-C coupling reactions. It is believed that the nitrile groups coordinate to the PdNP surface, which results in PdNP stabilization [33h].

Palladium acetate led to the formation of PdNPs in the presence of the IL 1,3dibutylimidazolium salts. It was suggested that formation of $\mathrm{N}$-heterocyclic Pdcarbene complexes is at the origin of the formation of PdNPs that catalyze Suzuki coupling [33i]. Such carbene complexes were shown to form and also catalyze the Heck reaction, formation of PdNPs under these conditions being highly suspected to be responsible for catalysis [33e,j]. Indeed, heating these $N$-heterocyclic Pdcarbene complexes led to PdNP formation subsequent to ligand loss (Scheme 1.7). The selectivity of the reactions in such IL media also depends on the solubility, and the solubility difference can be used for the extraction of the product $[33 \mathrm{k}-\mathrm{m}]$.

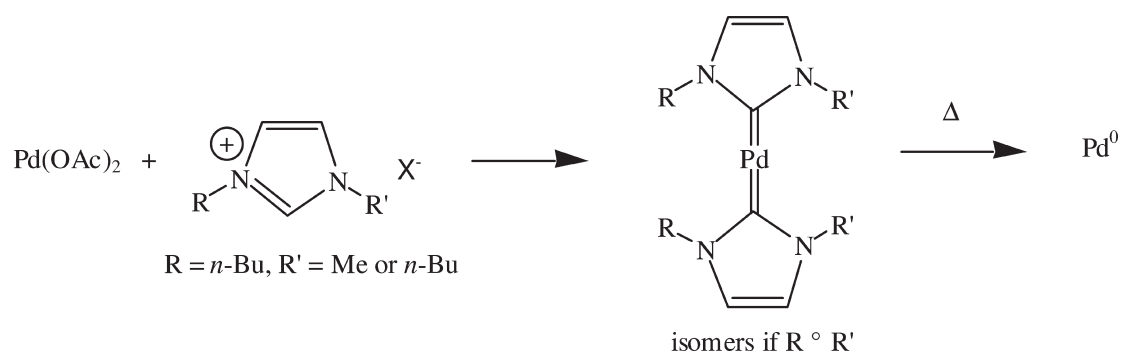

Scheme 1.7 Formation of Pd-carbene complexes by reaction between palladium acetate and imidazolium salts followed by decomplexation at high temperature and formation of catalytically active PdNPs for Heck-type reactions $[33 \mathrm{e}, \mathrm{i}, \mathrm{j}]$. 
In conclusion, IL are favorable media for the electrostatic stabilization of preformed NPs at room temperature and subsequent catalysis, whereas they give for instance Pd-carbene complexes upon deprotonation of the imidazolium cation, yielding, at high temperature, PdNP catalysts whose mechanism of action is discussed in the ligand-free catalysis section.

The field of ionic-liquid-stabilized NPs is reviewed by Jairton Dupont and D. Dagoberto de Oliveira Silva in Chapter 6, including the supramolecular aspects of ILs (multiple H-bonding) and the most frequent examples of reactions that are catalyzed by IL-stabilized NPs (hydrogenation of olefins, diolefins, arenes and ketones, hydroformylation, Heck reaction and Negishi coupling).

\section{9}

\section{Oxide Supports for NP Catalysts}

There is a fast growing and now large body of literature reports concerning NPs supported on metal oxides with a variety of supports, i.e. oxides of $\mathrm{Si}$ [34, 35], Al [36], $\mathrm{Ti}$ [37], $\mathrm{ZrO}_{2}$ [43], $\mathrm{Ca}$ [38], $\mathrm{Mg}$ [39, 43], and $\mathrm{Zn}$ [39h]. These oxides are in the form of $\mathrm{SiO}_{2}$ aerogels or sol-gels such as Gomasil G-200, high-surface silica (see for instance Scheme 1.8), M41S silicates and alumimosilicates, MCM-41 mesoporous silicates such as HMS and SBA-15 silica, silica spheres [35b], microemulsions $\left(\mathrm{SiO}_{2}\right)$, hydroxyapatite $\left(\mathrm{Ca}^{2+}\right)$ [38], hydrotalcite $\left(\mathrm{Mg}^{2+}, \mathrm{Al}^{3+}\right)$ [39], zeolites $\left(\mathrm{SiO}_{2}, \mathrm{Al}_{2} \mathrm{O}_{3}\right)$ [40], molecular sieves (Fig. 1.11) [41] and alumina membranes (Fig. 1.12) [36a]. Thus, despite the large variety of supports, the majority of them involve a form of silica. The catalytic reactions examined with these supported NPs are hydrogenation reactions of unsaturated substrates including selective ones, Heck and other $\mathrm{C}-\mathrm{C}$ coupling reactions and oxidation of $\mathrm{CO}$ and alcohols using molecular oxygen. The heterogenization of polymer- or dendrimer-stabilized NPs on a solid support such as silica permits one to benefit from the classic advantages of heterogeneous catalysis, i.e. stability to high temperatures and easy removal from the reaction medium and from the bottom-up approach of NP synthesis. A few remarkable recent examples are discussed below, and Table 1.1 gathers references for each NP-catalyzed reaction.

PtNPs and bimetallic dendrimer-stabilized Pd-AuNPs were adsorbed onto a high-surface silica support and thermally activated to remove the dendrimers



Scheme 1.8 Sequential allylic alkylation and Pauson-Khand reactions, both catalyzed by $\mathrm{Co}$ and PdNPs supported on silica for one-pot syntheses of bicyclic enones (Ref. 35c, Chung group, Org. Lett. 2002, 4, 4361). 



Molecular sieve
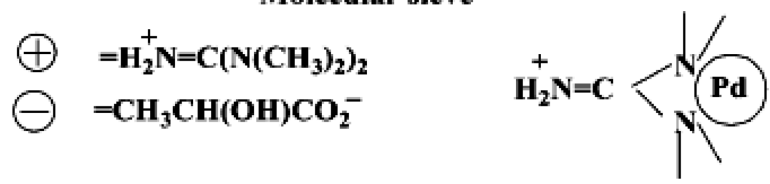

Fig. 1.11 Transmission electron micrograph (left) of a molecular sieve with supported PdNPs (right). The catalyst, active in hydrogenation of olefins, contains $20 \mathrm{wt} . \% \mathrm{IL}$ whose average layer thickness is $0.4 \mathrm{~nm}$. (Reprinted with permission from Ref. [41b], Han group, Angew.Chem. Int. Ed. 2004, 43, 1397).

Gas flow

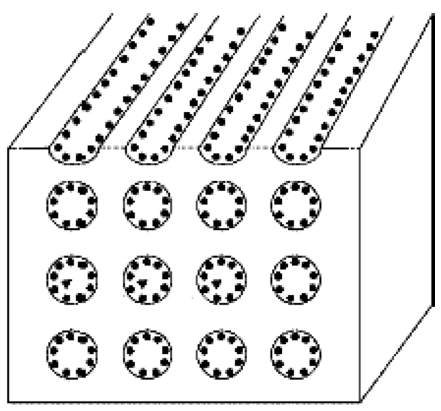

Fig. 1.12 Sketch of a piece of alumina membrane with metal NP elucidating its application for gas phase catalysis of 1,3butadiene hydrogenation (PdNPs) and CO oxidation (RuNPs) (Reprinted with permission from Ref. [36a], Schmid and Chaudret groups, Z. Anorg. Allg. Chem. 2004, 630, 1913).

(Fig. 1.13). The Chandler group showed that these NPs were smaller than $3 \mathrm{~nm}$ and highly active for $\mathrm{CO}$ oxidation catalysis near room temperature, and hydrogenation of toluene was also efficiently carried out [34]. The fabrication of uniform hollow spheres with nanometer to micrometer dimensions having tailored properties has recently been intensively studied using various procedures [42a]. Monodisperse Pd nanospheres of 300-nm size catalyzed Suzuki coupling of iodothiophene with phenylboronic acid using $3 \mathrm{~mol} \% \mathrm{Pd}$ catalyst in ethanol under reflux whereas $15 \mathrm{~mol} \% \mathrm{Pd}$ catalyst was used to couple bromobenzene under these conditions (Fig. 1.13) [35b]. Hydroxyapatite, $\left[\mathrm{Ca}_{10}\left(\mathrm{PO}_{4}\right)_{6}(\mathrm{OH})_{2}\right]$, with $\left[\mathrm{PdCl}_{2}\left(\mathrm{CH}_{3} \mathrm{CN}\right)_{2}\right]$ gives a 

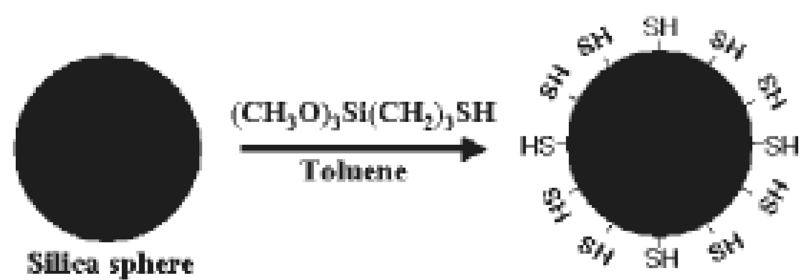

Siliea sphere
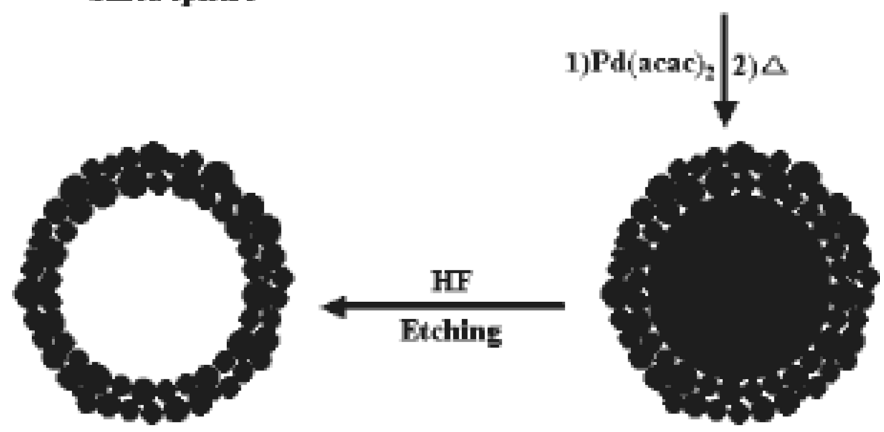

Fig. 1.13 Principle of the formation of hollow PdNP spheres used for the catalysis of Suzuki reactions in refluxing ethanol with $\mathrm{K}_{3} \mathrm{CO}_{4}$ as a base. With 2-iodothiophene and phenylboronic acid (catalyst: $3 \%$ Pd spheres), at least seven cycles could be achieved with 95-97\% yields (Reprinted with permission from Ref. [35b], Hyeon group, J. Am. Chem. Soc. 2002, 124, 7642).

monomeric $\mathrm{PdCl}_{2}$ species chemisorbed on the hydroxyapatite surface that is readily transformed into supported PdNPs with narrow size distribution in the presence of alcohol. These PdNPs catalyze the oxidation of 1-phenylethanol under an atmospheric $\mathrm{O}_{2}$ pressure in solvent-free conditions with a very high turnover up to 236000 and a remarkable turnover frequency of $9800 \mathrm{~h}^{-1}$. The work up is easy and the catalyst is recyclable without requiring additives to complete the catalytic cycles [38]. Hydrotalcite anionic clays are layered double hydroxides of formula $\mathrm{M}^{2+}{ }_{1-x} \mathrm{M}^{3+}{ }_{x}(\mathrm{OH})_{2}\left(\mathrm{An}^{-}\right)_{x / n} \cdot \gamma \mathrm{H}_{2} \mathrm{O}$ with $\mathrm{A}^{n-}=\mathrm{CO}_{3}{ }^{2-}, \mathrm{Cl}^{-}$or $\mathrm{NO}_{3}{ }^{-}$that have high anion exchange capacities. These materials, after calcination at temperatures over $723 \mathrm{~K}$, serve as supports for noble-metal catalysts. For instance, C-C coupling [39d] and selective semi-hydrogenation of alkynes [39e] have been obtained. Immobilization of a PdNP catalyst on a solid surface, such as molecular sieves, was achieved by the IL 1,1,3,3-tetramethylguadinidium lactate, and this system was used for solvent-free hydrogenation of alkenes with high activity and stability (for instance with a cyclohexene/Pd mol ratio of $12000,100 \%$ conversion was obtained in $10 \mathrm{~h}$ at $20^{\circ} \mathrm{C}$ with a TOF of $20 \mathrm{~min}^{-1}$ ) [41b]. The PdNPs of size $1-2 \mathrm{~nm}$ before and after catalysis, are stabilized by guanidinium ions [33d]. Ag-PdNPs prepared directly in ultrathin $\mathrm{TiO}_{2}$ gel films by a stepwise ion-exchange/reduction method showed activity in methyl acrylate hydrogenation 267 times higher than commercial Pd black and 1.6 times higher than PdNPs that did not contain Ag. This outstanding 
activity was explicable by the large fraction of the surface-exposed Pd atoms [37c]. Polyelectrolyte multilayers serve as supports for PdNP-catalyzed selective hydrogenation of allylic alcohols, isomerization being suppressed. Thus, polyacrylic acid and polyethyleneimine-Pd(II) complex were alternately adsorbed on 150-mm diameter alumina particles, and subsequent reduction of $\mathrm{Pd}(\mathrm{II})$ to PdNPs was carried out using $\mathrm{NaBH}_{4}$ [14d].

The mechanisms of oxide-supported PdNP catalysis are far from being understood. The oxide support has of course a strong influence on the activity. For instance, in the Heck reaction, the activity is dominated by the support according to:

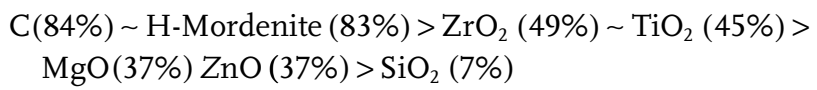

The good activity of zeolites in this reaction is seemingly due to better stabilization of active species in the cavities and to better dispersion of PdNPs on the oxide support. There are many heterogeneous catalysis studies discussing the influence of parameters (solvent, catalyst, base, temperature, recycling activity, NP size). Indeed, Djakovitch and Köhler have proposed that, since the results are often similar for homogeneous and heterogeneous systems in terms of selectivity, the heterogeneous mechanism proceeds by leaching of molecular Pd species into the solution, a phenomenon favored in DMF (see Chapter 10). This "leaching mechanism", first proposed by Julia et al. in 1973 [42b], then shown by Shmidt and Mametova [42c] and subjected to detailed experimental evidence by Arai [42d], is now firmly established [43a]. On the other hand, dehalogenation is favored on heterogeneous supports compared to homogeneous catalysis. Thus, it has been proposed that supported PdNPs are responsible for dehalogenation [43]. Along this line, the useful 3-phase test (also called Collman test, first proposed by Rebeck) has been used by Davies to discriminate homogeneous and heterogeneous Pdcatalyzed carbon-carbon coupling reactions [43k].

The heterogeneous Pd-catalyzed Heck reaction has been extended to important $\alpha$-arylated carbonyl derivatives, and the model arylation of diethylmalonate has been examined. The NaY-PdNP catalyst disclosed a limited activity, giving yields comparable to those obtained with the homogeneous $\left[\mathrm{Pd}(\mathrm{OAc})_{2} / 4 \mathrm{PPh}_{3}\right.$ ] system, but the Pd concentration used is only $2 \%$ and the recyclability is good. The amination of halogenoarenes has also been investigated with MgO-PdNPs and $\mathrm{ZrO}_{2}-$ PdNPs, the amphoteric supports giving the best yields, which would indicate that they favor the rate-limiting $\mathrm{C}-\mathrm{N}$ coupling in the reductive-elimination step. For this latter reaction, the zeolite supports give a better para selectivity, supposedly because of the optimal control of the "shape selectivity" [43, 44].

This leaching concept established for PdNPs applies to Ni/C for which catalysis of a variety of $\mathrm{C}-\mathrm{C}$ and $\mathrm{C}-\mathrm{N}$ coupling reactions (Kumada, Suzuki, Negishi, Heck, amination of bromoarenes) was also found by Lipshutz's group with leaching Ni species leading to a mixture of homogeneous and heterogeneous catalysis. However, the amount of leaching metal is much more important in the PdNP case 
than with NiNP for which the amount of leaching remained essentially constant and extremely low along the reactions [44k-o].

The Heck and Suzuki reactions have been catalyzed by other NPs such as RuNPs, including alumina-supported RuNPs [43c]. Hydroxyapatite-supported RuNPs were recently found to be efficient and recyclable catalysts for cisdihydroxlation and oxidative cleavage of alkenes [43d]. Supported RuNPs in the pores of mesoporous Al-MCM-41 materials were prepared by $\mathrm{H}_{2}$ reduction of adsorbed $\left[\mathrm{Ru}\left(\mathrm{NH}_{3}\right)_{6}\right]^{2+}$, and the activity in benzene hydrogenation was studied in the absence and presence of $330 \mathrm{ppm}_{2} \mathrm{~S}$ in $\mathrm{H}_{2}$. By comparison, zeolite-supported catalysts were found to be more efficient when $\mathrm{H}_{2} \mathrm{~S}$ was present [43d].

Oxide supports in transition-metal NP catalysis are discussed in this book in detail in Chapters 4, 5, 9, 10, 15, 16 and 17 dealing with heterogeneous catalysis. In particular, Florence Epron, Catherine Especel, Gwendoline Lafaye and Patrice Marécot review multimetallic NPs prepared by redox processes applied in catalysis in Chapter 9. This chapter is authored by the successors of Jacques Barbier who headed the Poitiers laboratory and pioneered oxide-supported multimetallic heterogeneous catalysis. It focuses on the advantages of silica- or alumina-supported multimetallic NP catalysts of organic transformations (particularly improvement in the selectivity of hydrogenation and hydrogenolysis and competition between $C=C$ and $C=O$ bond hydrogenation), naphtha reforming, fuel cells design and environmental catalysis. The strength of this chapter is also the systematic analysis of the redox approach to bi- and tri-metallic NPs coupled with compared catalytic efficiency. Practical aspects (including NP synthesis, stability in water, deposition reactions) and characterization methods and techniques are emphasized therein.

\subsection{0}

\section{Carbon Supports for NP Catalysts}

Charcoal is a classic commercial support for catalysts such as Pd/C. Bönnemann applied his general synthetic method using the reduction in THF of quaternary ammonium salts of metal cations to simple impregnation upon stirring the NP suspension on charcoal, and used these charcoal-supported metal NPs for a variety of catalyzed reactions [7, 29a, 34, 35a, 41a,c]. This procedure has also been used by Reetz for his electrochemically prepared metal NPs including catalytically active bimetallic NPs [8, 35a]. Activated carbons that are suitable as support materials in catalytic processes need to be prepared and modified in order to obtain adequate surface area, porosity and pore size distribution. Purification by acid treatment and elution processes is required in order to remove ash, extractable $\mathrm{sp}^{3}$ material and contaminants. These supports need pre-treatment and conditioning for the preparation of suitable surface chemistry to optimize precious metal/support interactions during impregnation and dispersibility in the reaction media. $P d / C$ catalysis (as well as overall PdNP catalysis) is extensively reviewed in Chapter 10 by Laurent Djakovitch, Klaus Köhler and Johannes G. de Vries. The mechanism is quasihomogeneous, and small Pd species in solution act as the catalytically active ones. 
The Pd is leaching and is redeposited at the end of the reaction, which provides an excellent recovery of the precious metal from the reaction mixture. The precipitation of the catalyst at the end of the reaction significantly changes its state and decreases its activity, however, making its re-use unattractive. Köhler et al. also showed that optimization of the Pd/C catalyst (temperature, solvent, base and Pd loading) allows turnover frequencies (TOFs) of up to 9000 to be reached and Pd concentration down to $0.005 \mathrm{~mol} \%$ to be developed for the Heck reaction of unactivited bromobenzene at $140^{\circ} \mathrm{C}$ [44]. The turnover numbers (TONs) are surpassed, however, by those of the best homogeneous catalysts.

Heterogeneous Ni/C catalysis is also essentially known for hydrogenation of unsaturated compounds. Recent reports concern hydrodehalogenation of aryl halides (including aryl chlorides), Kumada, Suzuki and Negishi-type C-C coupling and aromatic amination. Whereas the mechanism for heterogeneous hydrogenation follows true surface chemistry with dihydrogen chemisorption onto the metal surface, $\mathrm{C}-\mathrm{C}$ and $\mathrm{C}-\mathrm{N}$ coupling reactions involve nickel bleed from the carbon support (whose \% can be very high), a one-time event at the very beginning of the reactions. There exists an equilibrium for this homogeneous Ni species between $\mathrm{Ni}$ located inside or outside the $\mathrm{C}$ pores, strongly favoring the former. Thus, unlike in the $\mathrm{Pd} / \mathrm{C}$ case, only traces of metal are detectable in solution. The $\mathrm{Ni}$ is completely recovered on charcoal, making this heterogeneous catalyst important for applications. These reactions appear to be due to a combination of heterogeneous and homogeneous catalysis [44].

Recently, new supports such as high-area carbon have been used to prepare bimetallic Pt-Ru NPs that catalyze methanol electro-oxidation with enhanced activities compared to commercial catalysts [46i-1]. Pd, Rh and RuNPs, deposited onto functionalized carbon nanotubes through hydrogen reduction of metal- $\beta$ diketone precursors are effective catalysts for hydrogenation of olefins in $\mathrm{sc}^{-\mathrm{CO}_{2}}$. High electroactivity was also found in oxygen reduction for potential fuel cell application. Such PdNPs on carbon nanotubes in supercritical $\mathrm{CO}_{2}$ are efficient, for instance, in trans-stilbene hydrogenation [32g], and comparison between carbon nanotubes and activated carbon as support was carried out for Heck and Suzuki reactions, aerobic alcohol oxidation and selective hydrogenation [44].

Cuong Pham-Huu and Marc-Jacques Ledoux review carbon and silicon nanotubes containing catalysts in Chapter 7. The very high external surface of these carbon supports reduces the mass transfer limitations, and the specific interactions between the deposited phase and the support surface can explain the catalytic behavior. This chapter presents general background on the development of the catalytic synthesis of one-dimensional (1-D) carbon and carbide materials that are remarkably illustrated by outstanding images. It also compares carbon and silicon nanotubes containing catalysts to other supported catalysts. In particular, hydrogenation and dehydrogenation reactions of various substrates and desulfuration reactions are surveyed. Metal NPs and related materials supported on carbon nanotubes are also reviewed in a recent article by Compton's group with emphasis on the methods of functionalizing CNTs with metal NPs (including electrochemical, chemical and physical methods) and applications of CNTsupported NPs in catalysis, hydrogen sensing, sensing and energy storage [44r]. 
1.11

\section{NPs of Noble Metals (Ru, Rh, Pd, Pt and Their Oxides) in Catalysis}

Pioneers such as Nord in the 1940s and Turkevitch in the 1950s already used Pd as the metal of choice for the synthesis of NPs. Then, the reduction of halides of the transition metals and rare earth using $\mathrm{MBR}_{3} \mathrm{H}$ in THF by Bönnemann in the 1990s covered all the periodic table. The active NP catalysts that have been most studied, however, are those of the noble metals $\mathrm{Ru}, \mathrm{Rh}, \mathrm{Pd}, \mathrm{Pt}$ and $\mathrm{Au}$. Thus, the second part of this book includes a number of chapters that are devoted to one or two of these specific noble metals (a specific place is reserved thereafter for gold, vide infra). The most studied metal by far is Pd, because not only is it an excellent hydrogenation catalyst, but mainly it also catalyzes the formation of a large variety of $\mathrm{C}-\mathrm{C}$ bonds. Laurent Dajakovitch, Klaus Köhler and Johannes G. de Vries detail PdNP catalysis in Chapter 10. Alain Roucoux, Audrey Nowicki and Karine Philippot in Chapter 11 deal with RhNPs and RuNPs in catalysis with emphasis on soluble NPS in various liquid media (hydrogenation of alkenes, alkynes and aromatics and $C-C$ bond formations such as hydroformylation, methanol carbonylation, coupling reactions and Pauson-Khand reactions, oxidation, dehydrocoupling and hydrosilylation).

The seminal work by Reetz in the 1990s used the Bönnemann-type reduction of metal salts although cathodic reduction was the synthetic method of choice, and the catalytic activity of these and many other transition metals was demonstrated and used. Manfred T. Reetz details in Chapter 8 these studies devoted to size-selective synthesis of nanostructured metal-and metal-oxide colloids and their use as catalysts. It is shown in this Chapter 8 how $P d^{\text {II }}$ is reduced to $P d^{0}$ by the acetate anion (refer to Heck catalysis with PdNPs formed from $\left.\mathrm{Pd}(\mathrm{OAc})_{2}\right)$. Of particular interest is the clear relationship between the oxidation potential of the carboxplate anion $\mathrm{RCO}_{2}^{-}$and the size of the PdNPs formed. The more negative this potential, i.e. the larger the driving force for $P d^{I I}$ reduction, the smaller the PdNPs formed. Since it is known from Marcus theory that a larger driving force results in a faster reaction, this finding is in accord with the long-known observation that the NPs are larger if they are grown slowly using a weaker reductant whereas they are smaller using a stronger reductant. This is important, because small NPs are sought given their higher catalytic efficiency than that of larger ones. Serendipitous discovery of the aerobic oxidation of CoNPs to Co oxide NPs led the author to investigate and generalize to many metal NP oxides the formation of the $\mathrm{PtO}_{2} \mathrm{NPs}$ (Adams catalyst) from $\mathrm{PtCl}_{4}$ and a base in water in the presence of a stabilizer. This aspect concerning many mono- and di-metal NP oxides and their catalytic functions (chemical catalysis, electrocatalysis and corrosion) is the subject of the second part of Manfred Reetz' Chapter 8.

\subsection{2}

\section{Gold Nanoparticle-based Catalysts}

AuNPs occupy a special place given their great success and present developments. Thus, four chapters of the book are devoted to the various aspects of AuNP catalysis. In the AuNP-catalyzed $\mathrm{CO}$ oxidation to $\mathrm{CO}_{2}$ by $\mathrm{O}_{2}$ that can occur down to $200 \mathrm{~K}$ 
(!) [9c,d], the oxide support $\left(\mathrm{Fe}_{2} \mathrm{O}_{3}, \mathrm{TiO}_{2}\right.$ or $\left.\mathrm{Co}_{3} \mathrm{O}_{4}\right)$ is indispensable, a seminal discovery by Haruta in 1987 that was due to his recognition of the crucial requirement for the small size of the AuNPs $(<5 \mathrm{~nm})$ [9d,e, 45]. This surprising discovery, given the long believed chemical inertia of gold, has completely changed the way chemists look at this magic metal. The finding of low-temperature catalysis of $\mathrm{CO}$ oxidation is also of great interest, because the Pt/Pd catalysts that are used in cars for CO oxidation work only at temperatures above $200 \mathrm{~K}$. Thus, CO pollution essentially occurs during the first five minutes after starting the engines. The lowtemperature supported-AuNP catalyzed $\mathrm{CO}$ oxidation obviously could solve this problem. In addition, the selective oxidation of $\mathrm{CO}$ by $\mathrm{O}_{2}$ in the presence of $\mathrm{H}_{2}$ allows the purification of $\mathrm{H}_{2}$ from residual $\mathrm{CO}$. There are many other challenges in catalytic oxidation chemistry that can be addressed using this type of catalyst (vide infra). It is considered that, among the various ways to prepare supported AuNP catalysts, Haruta's deposition-precipitation procedure is the most suitable [9d]:

$\mathrm{HAuCl}_{4 \mathrm{aq}}+\mathrm{NaOH} \rightarrow\left[\mathrm{Au}(\mathrm{OH})_{4}\right]^{-} \mathrm{Na}_{\text {aq }}^{+}\left(\mathrm{pH}\right.$ 6-10) $\rightarrow \mathrm{Au}(\mathrm{OH})_{3} /$ Support $\rightarrow$ wash, dry then calcinate at 563-673 K $\rightarrow$ AuNP/Support (optimal AuNP size: $3 \mathrm{~nm}$, stable hemispherical NPs, the size being controlled by the calcination temperature whose optimum is $570 \mathrm{~K}$, optimal support: $\mathrm{TiO}_{2}$ for which the addition of $\mathrm{Mg}$ citrate is necessary during or after co-precipitation for a good dispersion of tiny AuNPs). The mechanism of $\mathrm{CO}$ oxidation is not clear, however [45a].

It has been shown that oxidation of $\mathrm{CO}$ by $\mathrm{O}_{2}$ to $\mathrm{CO}_{2}$ can also be catalyzed by the cluster $\mathrm{Au}_{6}{ }^{-}$in the gas phase (Fig. 1.14) [45c], and calculations with $\mathrm{Au}_{10}$ predict $\mathrm{CO}$ oxidation by $\mathrm{O}_{2}$ below room temperature [45d]. Recent studies by Haruta's

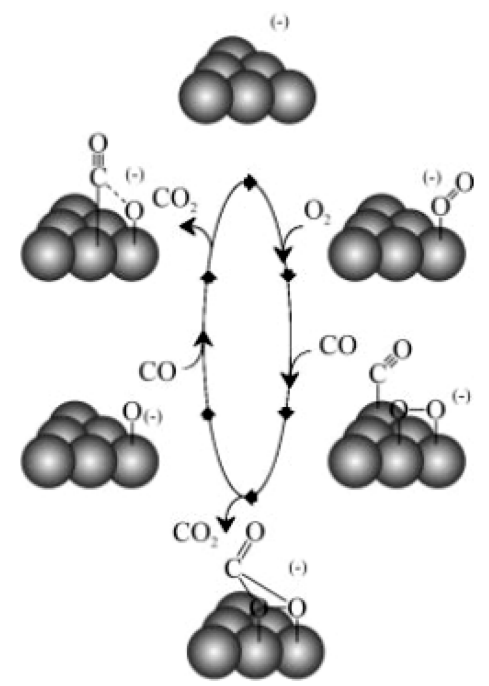

Fig. 1.14 Proposed schematic mechanism of the $\mathrm{Au}_{6}{ }^{-}$catalyzed formation of $\mathrm{CO}_{2}$ from $\mathrm{CO}$ and $\mathrm{O}_{2}$ in the gas phase (Reprinted with permission from Ref. [44c], Wallace and Whetten, J. Am. Chem. Soc. 2002, 124, 1999). 
group indicate that the TOF increases together with a decrease in AuNP diameter. The enhancing effect of moisture on the metal oxide support has been demonstrated. Kinetics showed that the rate of $\mathrm{CO}$ oxidation is independent of the $\mathrm{CO}$ concentration and only slightly dependent on the $\mathrm{O}_{2}$ concentration (of the order of 0 to 0.25 ) in the low concentration range down to 0.1 vol\%. Although the mechanism was thus eventually depicted with AuNPs alone [45c,d] (Fig. 1.14), activation by the oxide support is also needed and must be involved in the mechanism. Haruta suggested that $\mathrm{CO}$ probably adsorbs on the edge and step sites of AuNP surfaces and $\mathrm{O}_{2}$ adsorbs on the support surfaces [50b]. Both $\mathrm{CO}$ and $\mathrm{O}_{2}$ must be adsorbed on the catalyst surface near saturation and the rate-determining step must be the reaction between the two adsorbed species. [9d,e, 45b]. The support may also have a crucial role in the cleavage of the superoxide species or negatively polarized oxygen atom of the $\mathrm{O}_{2}$ molecule before, during or after $\mathrm{CO}$ binding [45]. Haruta recently depicted his mechanistic proposal as follows [11j]:

$$
\begin{array}{ll}
\mathrm{O}_{2}+\mathrm{Au}_{\mathrm{NP}} / \mathrm{TiO}_{2} & \rightarrow \mathrm{Au}_{\mathrm{NP}} / \mathrm{TiO}_{2} \ldots \mathrm{O}_{2} \\
\mathrm{Au} / \mathrm{TiO}_{2} \ldots \mathrm{O}_{2}+2 \mathrm{Au}_{\mathrm{NP}} \mathrm{CO} & \rightarrow \mathrm{OCAu}_{\mathrm{NP}}=\mathrm{O}+\mathrm{CO}_{2}+\mathrm{TiO}_{2} \\
\mathrm{OCAu}_{\mathrm{NP}}=\mathrm{O} & \rightarrow \mathrm{Au}_{\mathrm{NP}}+\mathrm{CO}_{2}
\end{array}
$$

Intriguingly, the Corma group reported that $\mathrm{Au}^{3+}$ on $\mathrm{CeO}_{2}$ catalyzed the homocoupling of phenylboronic acid, and the mechanism was proposed to involve $\mathrm{Au}^{3+}$ and $\mathrm{Au}^{+}$interconversion in the catalytic cycle [449]. Spectroscopic studies, by the same research group, of $\mathrm{Au}$ supported on nanocrystalline $\mathrm{CeO}_{2}$ showed that $\mathrm{CO}$ was bonded to $\mathrm{Au}^{3+}, \mathrm{Au}^{+}$and $\mathrm{Au}^{0}$ species, whereas the active form of $\mathrm{O}_{2}$ was bonded to $\mathrm{CeO}_{2}$ as superoxide $\eta^{1}-\mathrm{O}_{2}^{-}$confirming the nucleophilic attack of the electrondeficient carbon atom of $\mathrm{CO}$ by superoxide on the way to $\mathrm{CO}_{2}$ [449]. Another open question concerns the oxide support: is it best to use a redox active, thus reducible, oxide such as $\mathrm{TiO}_{2}$ or a redox inactive one such as silica or alumina?

Applications are expected in both the catalytic removal of $\mathrm{CO}$ produced at ambient temperature by engines and the removal of $\mathrm{CO}$ traces from dihydrogen streams feeding the fuel cells. There is a tremendous recent increase in the number of reports focusing on this area of supported AuNP-catalyzed CO oxidation, $\mathrm{TiO}_{2}$ becoming the dominant support [45].

The field of $\mathrm{CO}$ oxidation, including Masatake Haruta' systems, recent advances and key mechanistic issues are reviewed by Catherine Louis in Chapter 15. This chapter details the basic features of $C O$ oxidation catalyzed by AuNPs, the preparation of the oxide supports, conditions for efficient catalysis, electronic and morphological properties of the catalytically active supported AuNPs. It also offers deep and rational mechanistic discussions including the influence of the nature of the support.

Besides CO oxidation, other supported-AuNP catalyzed reactions have recently been disclosed, confirming that supported AuNPs are now a very popular means to catalytically activate dihydrogen and dioxygen:

- hydrogenation of 1,4-butadiene to butenes [46a], acrylaldehyde to allylic alcohol [46b], citral to geraniol + nerol [46c] and benzalacetone to phenyl-3-butene-2-ol [46d]. 
- oxidation (using $\mathrm{O}_{2}$ or air) of alcohols to aldehydes [46c], o-

hydroxybenzyl alcohol to salicylic aldehyde [46d], ethane-1,2-

diol to glycolate [46c], other diols to

hydroxymonocarboxylates [46e], $\beta$-amino alcohols to $\beta$ -

amino-acids [46e], aliphatic aldehydes to carboxylic acids

[46e], D-glucose to gluconic acid [46e] or oxalate [46m],

dihydrogen to hydrogen peroxide [45f], aromatic amines

(with $\mathrm{CO}$ ) to carbamate [46g], propene to propene oxide

[45h] and cyclohexane to cyclohexol and cyclohexanone

[46n-o]. Alcohols, in particular methanol are also oxidized

electrochemically, supported AuNPs being more active

electrocatalysts than AuNPs alone [47].

Other applications of supported-AuNP catalyzed reactions are numerous. They include:

- Oxidative decomposition by $\mathrm{Fe}_{2} \mathrm{O}_{3}$-supported AuNPs of bad-

smelling alkylamines responsible for the unpleasant

atmosphere in toilets [9d].

- Oxidative decomposition of dioxin coming from incinerator outlet gases by $\mathrm{La}_{2} \mathrm{O}_{3}$-supported AuNPs integrated with $\mathrm{Pd} /$

$\mathrm{SnO}_{2}$ and $\mathrm{Ir} / \mathrm{La}_{2} \mathrm{O}_{3}[9 \mathrm{~d}]$.

- Direct epoxidation of propylene to propylene oxide by $\mathrm{TiO}_{2}$

(MCM48)-supported AuNPs [9d], sensors able to

simultaneously detect $\mathrm{H}_{2}$ and $\mathrm{CO}$ at low level using $\mathrm{Co}_{2} \mathrm{O}_{3^{-}}$

supported AuNPs [9e].

- CO safety masks for efficient removal of CO from contaminated atmospheres [9e, 45f].

- Various liquid-phase synthetic processes.

Chapter 12 by Avelino Corma and Hermenegildo Garcia offers a remarkably broad and insightful overview and review of the general properties of AuNPs as catalysts for a variety of oxidation reactions including the role of templates and supports, with emphasis on ceria for which the Corma group has introduced seminal concepts. Sustainability, green chemistry aspects, comparison between PdNPs and AuNPs as aerobic oxidation catalysts, reaction mechanisms and prospects are also discussed in this chapter.

Chapter 13 by Cristina Della Pina, Ermelinda Falletta and Michele Rossi reviews AuNP catalyzed oxidations in organic chemistry including kinetic and mechanistic studies of the AuNP catalyzed oxidation of glucose, alcohols and aldehydes with emphasis on the original work emanating from Rossi's laboratory including seminal studies that have indeed largely contributed to these findings. Perspectives for industrial applications are also underlined in the conclusion.

Chapter 14 by Jun Kawahara and Masatake Haruta reviews AuNP-catalyzed propene epoxidation by dioxygen and dihydrogen. Propylene oxide, which is processed to polyurethane polyols and propylene glycols, is one of the most important chemical feedstocks whose efficient, free of side product and selective synthesis is highly challenging, the 
present world annual production being several million tons per year. This chapter includes catalyst preparation and catalytic tests from Masatake Haruta's laboratory with the AuNP-TiO 2 and AuNP-Ti-SiO ${ }_{2}$ systems, and detailed mechanistic discussions are presented in the conclusion.

\subsection{3}

\section{Environmental Problems: NOx Pollution and How to Remove NOx Using NP Catalysis}

Nitrogen oxides, in particular $\mathrm{NO}$ and $\mathrm{NO}_{2}$, are produced by fossil fuel burning, simple strong heating of air and, in particular, car exhaust systems. Thus, the two sources of NOx pollution are factories and cars. Therefore, depollution from nitrogen oxides is a must for our modern Society that still needs considerable improvement, as can be frequently considered by exaggerated air pollution in specific regions with a high density of factories and/or urban population and car traffic. The "DeNOx" process, i.e. the removal of nitrogen oxides, is possible using catalysis by transition-metal NPs, and the nanosize of metal NPs is actually a crucial parameter in this catalysis. Today industrial catalysts in use for "selective catalytic reduction" (SCR) are based on $\mathrm{TiO}_{2}$-supported $\mathrm{V}_{2} \mathrm{O}_{5}-\mathrm{WO}_{3}$ and/or $\mathrm{V}_{2} \mathrm{O}_{5}-\mathrm{MoO}_{3}$, but deNOx of car exhaust is still unresolved and under investigation. The three-way catalyst (TWC) based on combinations of $\mathrm{Pt}, \mathrm{Pd}$ and $\mathrm{Rh}$ is efficient to remove $\mathrm{CO}$ and NOx from gasoline engines at $400^{\circ} \mathrm{C}$ to $800^{\circ} \mathrm{C}$, but the period of time needed to reach these temperature involves pollution, and TWCs are ineffective for diesel and lean-burn gasoline engines.

Thus, Chapter 16 by Frédéric Thibault-Starzyk, Marco Daturi, Philippe Bazin and Olivier Marie is very important with regard to this problem, as it reviews NO heterogeneous catalysis viewed from the angle of NPs. In particular, this chapter presents the up-to-date research in progress concerning the size, stability, sintering and morphology of the NPs, metal NPs in zeolites, the role of TEM studies and of the ceria and zirconia supports, new catalytic NPs and materials such as Ga-Al-Zn complex oxides and carbon nanotubes supports for phosphotungstic acid.

For various other environmental problems, see also Chapters 9 and 18.

\subsection{4}

\section{Hydrocarbon Reforming: Activation of Hydrocarbons by NP Catalysts}

Hydrocarbon reforming is an essential industrial process that was carried out 50 years ago using simple oxide materials. For instance, the first performed reactions using Pt-supported alumina in a flow reactor were carried out by Gault's group in Strasbourg, and mechanistic studies of hexane isomerization using such catalysts were pioneered at that time. Sophisticated noble metal NPs are now used, and up-to-date research connects selectivity to mean NP size and morphological 
aspects. Model studies using nanocrystals as well as supported NPs are helpful in order to understand and optimize these selectivities, for instance in alkane isomerization reactions. Chapter 17 by François Garrin and Pierre Legaré, the successors of Gault in the Strasbourg laboratory, reviews hydrocarbon catalytic reactivity of supported metal NPs with emphasis on the progress concerning the understanding of the catalytic behavior under a reductive atmosphere and the influence of NP size, electronic structure and morphology.

It is also interesting to compare this "heterogeneous" NP approach to that involving organometallic surfaces catalysis developed by Basset's group. In this approach, the catalyst is molecular and anchored to silica via $\mathrm{Si}-\mathrm{O}-\mathrm{metal}$ bridges. For instance, $\left[\right.$ silica $\left.(\mathrm{SiO})_{2} \mathrm{Ta}^{\mathrm{III}}-\mathrm{H}\right]$ catalyzes propane metathesis to ethane and $n$-butane with turnover numbers between 25 and 60 at only $150^{\circ} \mathrm{C}$. This surface catalyst is generated from organometallic surface-bound precursors such as $\left[\right.$ silica $\left.(\mathrm{SiO}) x \mathrm{Ta}^{\mathrm{V}}(=\mathrm{CH} t-\mathrm{Bu})\left(\mathrm{CH}_{2} t-\mathrm{Bu}\right)_{3-} x\right], x=1$ or 2 that are the silica-surface analogs of Schrock's seminal Ta alkylidene complexes. The mechanism is suggested to proceed by a series of $\sigma$-bond metathesis of $\mathrm{C}-\mathrm{H}$ bonds and $\alpha$ and $\beta$ eliminations whereas direct $\sigma$-bond metathesis of $\mathrm{C}-\mathrm{C}$ bonds in not favored. The $\alpha$-elimination from $\mathrm{d}^{2}$ metal-methyl or metal-alkyl species generates, respectively, $\mathrm{HTa}=\mathrm{CH}_{2}$ or $\mathrm{HTa}=\mathrm{CHR}$, and it is proposed that the mechanism then follows an alkene metathesis pathway with olefins generated by $\beta$-elimination (including metallacyclobutane intermediates as in the Chauvin mechanism).

Thus, only $\sigma$-bond metathesis of two kinds of $\sigma$ bonds is observed in these systems: $\mathrm{H}-\mathrm{H}$, and $\mathrm{C}-\mathrm{H}$ involving Ta $\cdots \mathrm{C} \cdots \mathrm{H}$ interaction but not Ta $\cdots \mathrm{H} \cdots \mathrm{C}$, because a negatively polarized pentacoordinated carbon intermediate is not favorable (Scheme 1.9) [82].

As in Pd catalysis, molecular and NP catalysts are complementary rather than competitive, because molecular catalysts are either excellent models allowing us to improve our understanding or their ligands can still so far improve on the performances of NP catalysis in terms of selectivities. This comparison thus represents a challenge for the heterogeneous community.



$\mathrm{H}-\mathrm{H}$ bond activation giving a Ta-hydride species

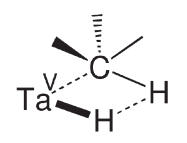

C-H bond activation of alkanes giving a Ta-alkyl and $\mathrm{H}_{2}$



reverse $\mathrm{C}-\mathrm{H}$ bond activation not observed due to a penta-coordinated $\beta$ carbon

Scheme 1.9 Hydrogenolysis of Ta-alkyl and methanolysis of $\mathrm{Ta}-\mathrm{H}$ by $\sigma$-bond metathesis for alkane disproportionation disclosed by Basset's group [50] with the silica-supported catalyst $\left[(\mathrm{SiO}) x \mathrm{Ta}^{\mathrm{v}}(=\mathrm{CH}-\mathrm{t}-\mathrm{Bu})\left(\mathrm{CH}_{2} \mathrm{tBu}\right)_{3-\mathrm{x}}\right]$. 
1.15

\section{Surface Organometallic Chemistry on Metal NPs}

In pursuing the introduction of the contributions by Basset's group, it should be emphasized that organometallic chemistry and catalysis on oxides (vide supra) has its counterpart here with the related concept involving organometallic chemistry and catalysis using organometallic complexes deposited on metal NPs. Indeed, in the last (but not least!) chapter of this book, Chapter 18, Katrin Pelzer, Gregory Godard, Jean-Pierre Candy and Jean-Marie Basset offer an overview of this area with three types of materials devoted to both catalysis (hydrogenation, hydrogenolysis, deshydrogenation, isomerization) and environmental chemistry (dearsenification and demercurisation of crude-oil, extraction of heavy metals from contaminated water):

1. A material in which a surface organometallic fragment is linked to the metallic nanoparticle via "covalent" bonds.

2. A material in which a "naked" adatom is located on the metal NP surface.

3. A material in which the "adatoms" are incorporated in the NP yielding a bulk alloy.

$\mathrm{Rh}, \mathrm{Pt}, \mathrm{Ru}$, and Ni NPs with $\mathrm{Sn}, \mathrm{Ge}, \mathrm{As}, \mathrm{Hg}$ organometallic complexes are discussed with these processes.

\subsection{6}

\section{Application and Perspectives in Organic Chemistry}

The finding of catalytic formation of $\mathrm{C}-\mathrm{C}$ and $\mathrm{C}-\mathrm{N}$ bonds by $\mathrm{Pd}$ catalysts has been a considerable progress for organic chemistry in the last five years of the 20th century [34]. It became possible to easily functionalize olefins, alkynes and aromatics. Yet, the problem of catalyst recovery and pollution by phosphine was unsolved. These aspects are crucial for the pharmaceutical industry, the inclusion of metal and phosphine contaminants in drugs being unacceptable. NP-supported catalysis with $\mathrm{Pd}, \mathrm{Ni}$ and eventually other metals now provides a very satisfying solution to catalyst removal from the reaction mixture by simple filtration, because the carbon and $\mathrm{NaY}$ zeolite support (the best ones) are reservoirs of metal species that retain these metal species subsequent to reaction in solution. The amount of metal left in solution is of the order of ppm. Moreover, such type of catalysis is phosphine free. Applications have started at DSM with the synthesis of kg-scale pharmaceutical intermediates, and it is likely that this type of procedure will now spread at a high speed in the pharmaceutical and other industries. The Heck reaction, for instance, is a key reaction for the production of fine chemicals on a multi-ton scale per year [34a] such as the herbicide Prosulfuron ${ }^{\mathrm{TM}}$ [34b], the anti-inflammatory Naproxen $^{\mathrm{TM}}$ [34c] or the anti-asthma Singulair ${ }^{\mathrm{TM}}$ [34d]. On the other hand, in terms of "Green Chemistry", it is likely that procedures involving chemicals such as ionic 
liquids, micelles, surfactants and other additives in homogeneous solution will less retain the attention of those interested in atom economy problems and applicable organic synthesis.

So far, high-performance molecular catalysts, reported by the groups of Buchwald, Hartwig and $\mathrm{Fu}$, that are able to activate and functionalize chloroaromatics are complementary to PdNPs that cannot carry out this task, seemingly because the stereoelectronic requirement provided by the ligand (with electron donor groups to increase electron density needed in the oxidative addition step and the large bulk of these ligands required to facilitate the reductive elimination step) is essentially missing in NPs. Likewise, olefin and alkyne metathesis that has been a success story with molecular catalysts cannot be achieved with NPs, probably because alkylidenes bridge metal surface atoms instead of presenting monohapto doubly-bonded alkylidene ligands on single metal centers, which suppresses their metathesis reactivity in the presence of unsaturated hydrocarbons (see Garin's mechanism in Chapter 17 and Basset's concept for alkane activation, however).

Given the extraordinary present progression of AuNP-catalyzed reactions, it is obvious that many applications in oxidation catalysis will very soon penetrate the everyday world of organic chemists (as illustrated in this book). Thus, altogether, NP catalysis embraces an increasingly large part of organic reactions and is respectful of the "Green Chemistry" aspects.

\subsection{7}

\section{Conclusion}

The state of the art of metal NP design and catalysis is now well advanced thanks to the efforts of the pioneers and the advent of modern characterization techniques. A large variety of NP preparation modes and materials serve as supports or grafting cores, and several media compete for efficient catalytic processes. Monodisperse, small (1-10 nm) supported metal NPs, including bi-and trimetallic NP catalysts, most often more efficient than those containing only one type of metal, are available for many current reactions with great catalytic efficiency due to the enhanced available NP surface. Compared surface $(\operatorname{Pd}(1,1,1)$ single crystal) and PdNP studies of catalysis of alkene hydrogenation have even shown that only PdNPs catalyze this reaction [32i]. This progress has considerably improved the selectivity of NP catalyzed reactions, especially the hydrogenation of unsaturated substrates that proceeds truly heterogeneously. High enantioselectivity has been obtained, although the demonstration that asymmetric induction occurs at the metal NP surface rather than on the more reactive leaching liganded monometallic fragment is at least not obvious. For example, in the $\mathrm{Pd} / \mathrm{C}$ and $\mathrm{Ni} / \mathrm{C}$ catalyzed $\mathrm{C}-\mathrm{C}$ and $\mathrm{C}-\mathrm{N}$ bond-forming reactions, the mechanism involves such a leaching pathway with recovery of the metal on the support at the end of the reaction. More mechanistic studies are called for in order to understand the nature of the very active metal species in solution. On the side of efficiency, the activation of aryl chlorides for $\mathrm{C}-\mathrm{C}$ coupling reactions still remains a key challenge to match 
organometallic catalysts that are presently more efficient than metal NP catalysts. A major recent finding was the removal of these catalysts by filtration, although recycling and efficient re-use many times of supported NP catalysts remains a challenge. Along this line, magnetic separation of magnetic NP catalysts appears as a challenging solution [48].

Altogether, the field of metal NP catalysis is a fascinating one, as exemplified by the new gold rush and its very attractive perspectives in oxidation chemistry and by the ligand-free Pd and Ni catalysis using "homeopathic" amounts of catalyst. The metal NP field is presently burgeoning, and it is anticipated that these key challenges will be met in the close future, and that this area of nanoscience will be much more applied in tomorrow's laboratory and industry.

\section{References}

1 Catalysis by Metals and Alloys, V. Ponec, G. C. Bond (Eds.), Elsevier, Amsterdam, 1995, Vol. 95; G. C. Bond, Heterogeneous Catalysis: Principles and Applications, Oxford Science Publications, Clarendon Press, Oxford, 1987; Handbook of Heterogeneous Catalysis, G. Ertl, H. Knözinger, J. Vertkamp (Eds.), WileyVCH, Weinheim, 1997; R. J. Farauto, C. H. Bartholomew, Fundamentals of Industrial Catalytic Processes, Blackie Academic and Professional, London, 1997; J. M. Thomas, W. J. Thomas, Principle and Practice of Heterogeneous Catalysis, VCH, Weinheim, 1997; C. R. Henry, Appl. Surf. Sci. 2000, 164, 252; T. P. St Clair, D. W. Goodman, Top. Catal. 2000, 13, 5; M. Bowker, R. A. Bennet, A. Dickinson, D. James, R. Smith, P. Stone, Stud. Surf. Sci. Catal. 2001, 133, 3; M. Kralik, A. Biffis, J. Mol. Catal. A: Chem. 2001, 177, 113; J. Thomas, R. Raja, Chem. Rec. 2001, 1, 448; C. Mohr, P. Claus, Sci. Prog. 2001, 84, 311; J. M. Thomas, B. F. G. Johnson, R. Raja, G. Sankar, P. A. Migley, Acc. Chem. Res. 2003, 36, 20; O. Alexeev, B. C. Gates, Ind. Eng. Chem. Res. 2003, 42, 1571.

2 Applied Homogeneous Catalysis with Organometallic Compounds, B. Cornils, W. A. Herrmann (Eds.), Wiley-VCH, Weinheim, Vol. 1 and 2, 1996; W. A. Herrmann, B. Cornils, Angew.Chem. Int. Ed. Engl. 1997, 36, 1049; Metal-Catalyzed Cross-Coupling Reactions F. Diederich, P. J. Stang (Eds.), Wiley-VCH, Weinheim,
1998; Metal-Catalyzed Cross-Coupling Reaction, Vol. 1 and 2, A. de Mejere, F. Diederich (Eds.), Wiley-VCH, Weinheim, 2004; J. A. Gladysz, Pure Appl. Chem. 2001, 73, 1319; J. Gladysz, Introduction to the special issue of Chem. Rev. 2002, 102(10) 3215-3892, J. Gladysz (Ed.) dedicated to recoverable catalysts; D. Astruc, Organometallic Chemistry and Catalysis, Springer, Heidelberg, 2007 (Parts 4 and 5).

3 For recent reviews on transition-metal NPcatalyzed reactions, see: D. Astruc, F. Lu, J. Ruiz Aranzaes, Angew. Chem. Int. Ed. 2005, 44, 7399; J. G. De Vries, Dalton Trans. 2006, 421; D. Astruc, Inorg. Chem. 2007, 46, 1884.

4 Nanoparticles and Nanostructured Films. Preparation, Characterizations and Applications, J. H. Fendler (Eds.), WileyVCH, Weinheim, Germany, 1998; G. Schmid in Nanoscale Materials in Chemistry, K. J. Klabunde (Eds.), WileyInterscience, New York, 2001, pp. 15-59; R. G. Finke in Metal Nanoparticles. Synthesis, Characterizations and Applications, D. L. Feldheim, C. A. Foss, Jr., (Eds.), Marcel Dekker, New York, 2002, Ch. 2, pp. 17-54; A. Wieckowski, E. R. Savinova, C. G. Vayenas, Catalysis and Electrocatalysis at Nanoparticle Surfaces, Marcel Dekker, New York, 2003, p. 970; Nanoparticles, G. Schmid (Eds.), WileyVCH, Weinheim, 2004.

5 Early reviews on NP catalysis: (a) J. B. Michel, J. T. Scharz, in Catalyst Preparation 
Science, IV, B. Delmon, P. Grange, P. A. Jacobs, G. Poncelet (Eds.), Elsevier, Amsterdam, 1987, pp. 669-687; (b) G. Schmid, Chem. Rev. 1992, 92, 1709; (c) L. N. Lewis, Chem. Rev. 1993, 93, 26932730; (d) J. S. Bradley in Clusters and Colloids, Ed. G. Schmid (Ed.), VCH, Weinheim, 1994, Ch. 6, pp. 459-544; (e) Catalysis by Di-and PolynuclearMetal-Cluster Complexes, L. N. Lewis, R. D. Adams, F. A. Cotton (Eds.), Wiley-VCH, New York, 1998, p. 373; (f) N. Toshima in Fine Particles Sciences and Technology - From Micro- to New Particles, E. Pellizzetti (Ed.), Kluwer: Dordrecht, 1996, pp. 371-383; (g) N. Toshima, T. Yonezawa, New J. Chem. 1998, 11791201; Y. Shiraishi, N. Toshima, J. Mol. Catal. A: Chem. 1999, 141, 187; Y.

Shiraishi, N. Toshima, Colloid Surf. A 2000, 169, 59.

6 (a) H. Bönnemann, W. Brijoux, E. Dinjus, T. Fretzen, B. Joussen, J. Korall, Angew. Chem. Int. Ed. Engl. 1990, 29, 273; (b) H. Bönnemann, W. Brijoux, R. Brinkmann, E. Dinjus, T. Fretzen, B. Joussen, J. Korall, Angew. Chem. Int. Ed. Engl. 1992, 31, 323; H. Bönnemann, W. Brijoux in Active Metals: Preparation, Characterization, Applications, A. Fürstner (Ed.), VCH-Weinheim, 1996, pp. 339-379.

7 (a) M. T. Reetz, W. Helbig, J. Am. Chem. Soc. 1994, 116, 7401; (b) M. T. Reetz, S. A. Quaiser, Angew. Chem. Int. Ed. Engl. 1995, 34, 2240; (c) M. T. Reetz, W. Helbig, S. A. Quaiser, in Active Metals: Preparation, Characterization, Applications, A. Fürstner (Ed.), VCHWeinheim, 1996, pp. 279-297; (d) M. T. Reetz, R. Breinbauer, K. Wanninger, Tetrahedron Lett. 1996, 37, 4499; (e) M. T. Reetz, G. Lohmer, Chem. Commun. 1996, 1921; (f) for recent reports by Reetz's group on PdNP catalysis, see Refs. [31d,f,j,n, 41c].

8 (a) M.-C. Daniel, D. Astruc, Chem. Rev. 2004, 104, 293; (b) M. Faraday, Philos. Trans. 1857, 151, 183. (c) M. Brust, M. Walker, D. Bethell, D. J. Schiffrin, R. J. Whyman, J. Chem. Soc. Chem. Commun. 1994, 801; (d) D. I. Gittins, F. Caruso, Angew. Chem. 2001, 113, 3089; Angew. Chem. Int. Ed. 2001, 40, 3001; (e) T. W.
Smith, US Patent 4252671, 4252672,

4252673, 4252674 and 4252678, 1981;

(f) C. H. Griffiths, H. P. O'Horo, T. W.

Smith, J. Appl. Phys. 1979, 50, 7108; (g) M.

Kilner, G. J. Russell, S. Hoon, B. K.

Tanner, J. Mag. Mater. 1983, 39, 107; (h)

P. H. Hess, , P. H. Parker, J. Appl. Polym.

Sci. 1966, 10, 1915; (i) J. R. Thomas, J.

Appl. Phys. 1966, 37, 2914; (j) J. S. Bradley, J. M. Millar, E. W. Hill, S. Behal, B.

Chaudret, A. Duteil, Faraday Discuss. 1991, 92, 255; J. S. Bradley, E. W. Hill, S. Behal, C. Klein, B. Chaudret, A. Duteil, Chem. Mater. 1992, 4, 1234; (k) S. Roginsky, A. Schalnikoff, Kolloid Z. 1927, 43, 67; (1) J. R. Blackborrow, D. Young, Metal Vapor Synthesis, Springer Verlag, New York, 1979.

9 (a) L. D. Rapino, F. F. Nord, J. Am. Chem. Soc. 1941, 63, 2745 and 3268; K. E. Kavanagh, F. F. Nord, J. Am. Chem. Soc. 1943, 65, 2121; (b) D. Y. Cha, G. Parravano, J. Catal. 1970, 18, 320; G. Parravano, J. Catal. 1970, 18, 320; (c) M. Haruta, T. Kobayashi, H. Sano, N. Yamada, Chem. Lett. 1987, 405; M. Haruta, N. Yamada, T. Kobayashi, S. Lijima, J. Catal. 1989, 115, 301; observation of CO oxidation at $200 \mathrm{~K}$ : M. Haruta, S. Tsuboda, T. Kobayashi, H. Kagehiama, M. J. Genet, B. Demon, J. Catal. 1993, 144, 175; (d) M. Haruta, CATTECH, 2002, 6, 102; (e) for other excellent recent reviews on AuNP catalyzed $\mathrm{CO}$ oxidation by $\mathrm{O}_{2}$, see ref. $11 \mathrm{j}$, 50b and: T. V. Choudary, D. W. Goodman, Top. Catal. 2002, 21, 25; G. Schmid, B. Corain, Eur. J. Inorg. Chem. 2003, 3081; see also Ref. [8a] (f) G. C. Bond, P. A. Sermon, Gold Bull. 1973, 6, 102; (g) H. Hirai, Y. Nakao, N. J. Toshima, Macromol. Sci. Chem. 1978, A12, 1117 and 1979, A13, 727; (h) M. Boutonnet, J. Kizling, P. Stenius, G. Maire, Colloids Surf. 1982, 5, 209; M. Boutonnet, J. Kizling, R.

Touroude, G. Maire, P. Stenius, Appl. Catal. 1986, 20, 163; (i) K. Kurihara, J. H. Fendler, J. Am. Chem. Soc. 1983, 105, 6152; J. H. Fenler, P. Tundo, Acc. Chem. Res. 1984, 17, 3; J. H. Fendler, K. Kurihara, in Metal Containing Polymeric Systems, J. E. Sheats, C. E. Carraher, Jr., C. U. Pittman, Jr. (Eds.), Plenum Press, New York, 1985, pp. 341-353; (j) L. N. Lewis, N. Lewis, J. Am. Chem. Soc. 1986, 108, 7228. 
10 (a) A. Moradpour, E. Amouyal, P. Keller, H. Kagan, Nouv. J. Chem. 1978, 2, 547;

(b) A. Henglein, J. Phys. Chem. 1979, 83, 2858; (c) A. Henglein, J. Lillie, J. Am. Chem. Soc. 1981, 103, 1059; (d) K. Kurihara, J. H. Fendler, I. J. Ravet, Mol. Catal. 1986, 34, 325; (e) M. Boutonnet, J. Kizling, R. Touroude, G. Maire, P. Stenius, Appl. Catal. 1986, 20, 163; (f) Y. Degani, I. J. Willner, Chem. Soc., Perkin Trans. II 1986, 37; (g) I. Willner, R. Maidan, D. Mandler, H. Dürr, G. Dörr, K. Zengerle, J. Am. Chem. Soc. 1987, 109, 6080; (h) J. S. Bradley, E. W. Hill, M. E. Leonowitz, H. Witzke, J. Mol. Catal. 1987, 41, 59; (i) C. Larpent, H. Patin, J. Mol. Catal. 1988, 44, 191.

11 Recent reviews on NP catalysis: Ref. [3] and (a) M. A. El-Sayed, Acc. Chem. Res. 2001, 34, 257; (b) R. M. Crooks, M. Zhao, L. Sun, V. Chechik, L. K. Yeung, Acc. Chem. Res. 2001, 34, 181; (c) T. Yonezawa, N. Toshima, PolymerStabilized Metal Nanoparticles: Preparation, Characterization and Applications, in Advanced Functional Molecules and Polymers, H. S. Nalwa (Ed.), OPA N.V., 2001, Vol. 2, Ch. 3, pp. 65-86; A. B. R. Mayer, Polym. Adv. Technol. 2001, 12, 96; (d) H. Bönnemann, R. Richards, Synth. Methods Organomet. Inorg. Chem. 2002, 10, 209; (e) A. Roucoux, J. Schulz, H. Patin, Chem. Rev. 2002, 33, 27-36. (f) I. I. Moiseev, M. N. Vargaftik, Russ. J. Chem. 2002, 72, 512; (g) A. T. Bell, Science 2003, 299, 1688;

(h) M. Moreno-Manas, R. Pleixats, Acc. Chem. Res. 2003, 36, 638-643; (i) B. F. G. Johnson, Top. Catal. 2003, 24, 147 (j) AuNP-catalyzed CO oxidation: M. Haruta, J. New Mater. Electrochem. Syst. 2004, 7, 163; (k) J. A. Widegren, R. G. Finke, J. Mol. Catal. A Chem. 2003, 198, 317; J. A. Widegren, R. G. Finke, Inorg. Chem. 2002, 41, 1558; (b) C. Besson, E. E. Finney, R. R. Finke, J. Am. Chem. Soc. 2005, 127, 8179; C. Besson, E. E. Finney, R. R. Finke, Chem. Mater. 2005, 17, 4925.

12 (a) X.-D. Mu, D. G. Evans, Y. Kou, Catal. Lett. 2004, 97, 151; (b) P. Claus, A. Brückner, C. Möhr, H. Hofmeister, J. Am. Chem. Soc. 2000, 122, 11430; (c) A.I. Kozlov, A. P. Kozlova, K. Asakura, Y.
Matsui, T. Kogure, T. Shido, Y. Iwazawa, J. Catal. 2000, 196, 56; (d) A. Martino, S. A. Yamanaka, J. S. Kawola, D. A. Ly, Chem. Mater. 1997, 9, 423; (e) T. Li, J. Moon, A. A. Morrone, J. J. Mecholsky, D. R. Talham, J.-H. Adair, Langmuir 1999, 15, 4328; (f) U.-A. Paulus, U. Endruschat, G.-J. Feldmeyer, T.-J. Schmidt, H. Bönnemann, J.-J. Behm, J. Catal. 2000, 195, 383; (g) Y. Mizukoshi, R. Oshima, Y. Mizukoshi, Y. Nagata, Languir. 1999, 8, 2733. (h) S. Papp, I. Dekany, Colloid Polym. Sci. 2001, 279, 449; (i) C. B. Hwang, Y.-S. Fu, Y.-L. Lu, S.-W. Jang, P.-T. Chou, C.-R. Wang, S.-J. Yu, J. Catal. 2000, 195, 336; (j) K.-T. Wu, Y.-D. Yao, C.-R. C. Wang, P. F. Chen, E.-T. Yeh, J. Appl. Phys. 1999, 85, 5959; (k) R. P. Andres, J.-D. Bielefeld, J.-I. Henderson, D.-B. Janes, V.-R. Kolagunta, C.-P. Kubink, W. Mahoney, R.-G. Osifchin, R. Reifenberger, Science 1996, 273, 1690.

13 (a) R. Narayanan, M. A. El-Sayed, J. Am. Chem. Soc. 2003, 125, 8340; (b) Y. Li, E. Boone, M. A. El-Sayed, Langmuir 2002, 18, 4921.

14 (a) S. V. Ley, C. Mitchell, D. Pears, C. Ramarao, J.-Q. Yu, W.-Z. Zhou, Org. Lett. 2003, 5, 4665; (b) M. M. Demir, M. A. Gulgun, Y. Z. Menceloglu, B. Erman, S. S. Abramchuk, E. E. Makhaeva, A. R. Khokhlov, V. G. Matveeva, M. G. Sullman, Macromolecules 2004, 37, 1787. (c) L. R. Gröschel, A. Haidar, K.-H. Beyer, R. Reichert, R. Schomäcker, Catal. Lett. 2004, 95, 67; (d) S. Kidambi, J.-H. Dai, J. Lin, M. L. Bruening, J. Am. Chem. Soc. 2004, 126, 2658; (e) B. P. S. Chauhan, J. S. Rathore, T. Bandoo, J. Am. Chem. Soc. 2004, 126, 8493; (f) T. Sanji, Y. Ogawa, Y. Nakatsuka, M. Tanaka, H. Sakurai, Chem. Lett. 2003, 32, 980; (g) A. B. Lowe, B. S. Sumerlin, M. S. Donovan, C. L. McCormick, J. Am. Chem. Soc. 2002, 124, 11562; (h) A. Drelinkiewicza, A. Waksmundzka, W. Makowski, J. W. Sobczak, A. Krol, A. Zieba, Catal. Lett. 2004, 94, 143; (i) Y.-B. Liu, C. Khemtong, J. Hu, Chem. Commun. 2004, 398; (j) U. R. Pillai, E. Sahle-Demessie, J. Mol. Catal. 2004, 222, 153;

(k) M. Adlim, M. Abu Bakar, K. Y. Liew, J. Ismail, J. Mol. Catal. A. 2004, 212, 141; (1) D. Tabuani, O. Monticelli, A. Chincarini, C. Bianchini, F. Vizza, S. Moneti, S. Russo, 
Macromolecules 2003, 36, 4294; (m) C. C. Yang, C. C. Wan, Y. Y. Wang, J. Colloid Interface Sci. 2004, 279, 433.

15 J. H. Sinfelt, Acc. Chem. Res. 1977, 10, 15; J. H. Sinfelt, Bimetallic Catalyst: Discoveries, Concepts and Applications, Wiley, New York, 1983; J. H. Sinfelt, Int. Rev. Phys. Chem. 1988, 7, 281.

16 (a) J.-H. He, I. Ichinose, T. Kunitake, A. Nakao, Y. Shiraishi, N. Toshima, J. Am. Chem. Soc. 2003, 125, 11034; (b) Y. Shiraishi, D. Ikenaga, N. Toshima, Aust. J. Chem. 2003, 56, 1025; (c) R. Sablong, U. Schlotterbeck, D. Vogt, S. Mecking, Adv. Syn. Catal. 2003, 345, 333.

17 (a) Dendrimers and Nanosciences, D. Astruc (Ed.), C. R. Chimie, Elsevier, Paris, 2003, 6 (special issue: vol. 8-10); (b) G. R. Newkome, C. N. Moorefield, F. Vögtle, Dendrimers and Dendrons: Concepts, Synthesis, Applications, WileyVCH, Weinheim, 2001; (c) J. F. G. A. Jansen, E. M. M. de Brabander-van den Berg, E. W. Meijer, Science, 1994, 266, 1226; (d) D. A. Tomalia, A. M. Naylor, W. A. Goddard III, Angew. Chem. Int. Ed. Engl. 1990, 29, 138.

18 (a) M. Zhao, L. Sun, R. M. Crooks, J. Am. Chem. Soc. 1998, 120, 4877; M. Zhao, R. Crooks, Angew. Chem. 1999, 111, 375; Angew. Chem. Int. Ed. 1999, 38, 364; V. Chechik, M. Zhao, R. M. Crooks, J. Am. Chem. Soc. 1999, 121, 4910; M. Zhao, R. M. Crooks, Adv. Mater. 1999, 11, 217; V. Chechik, M. Zhao, R. M. Crooks, J. Am. Chem. Soc. 2000, 122, 1243; R. M. Crooks, M. Zhao, L. Sun, V. Chechik, L. K. Yeung, Acc. Chem. Res. 2001, 34, 181; L. K. Yeung, R. M. Crooks, Nano Lett. 2001, 1, 14; L. K. Yeung, C. T. Lee, K. P. Jonston, R. M. Crooks, Chem. Commun. 2001, 2290; R. W. Scott, A. F. Datye, R. M. Crooks, J. Am. Chem. Soc. 2003, 125, 3708; Y. Niu, R. M. Crooks, in Dendrimers and Nanosciences, D. Astruc (Ed.), C. R. Chimie, Elsevier, Paris, 2003, 6, 1049; R. W. Scott, O. M. Wilson, S.-K. Oh, E. A. Kenik, R. M. Crooks, J. Am. Chem. Soc. 2004, 126, 15583; Y.-G. Kim, S.-K. Ho, R. M. Crooks, Chem. Mater. 2004, 16, 167; R. W. J. Scott, C. Sivadinarayana, O. M. Wilson, Z. Yan, D. W. Goodman, R. M. Crooks, J. Am.
Chem. Soc. 2005, 127, 1380; J.-H. Liu, A.Q. Wang, Y.-S. Shi, H.-P. Lin, C.-Y. Mou, J. Phys. Chem. B 2005, 109, 40; O. M. Wilson, M. R. Knecht, J. C. GarciaMartinez, R. M. Crooks, J. Am. Chem. Soc. 2006, 128, 4510: (b) E. Kunio, M. Keiko, Y. Tomokazu, J. Colloid Interfac. Sci. 2002, 254, 402; (c) J. Lemo, K. Heuze, D. Astruc, Inorg. Chim. Acta 2006, 359, 4909.

19 (a) L. Balogh, D. A. Tomalia, J. Am. Chem. Soc. 1998, 120, 7355; (b) L. Balogh, D. R. Swanson, D. A. Tomalia, G. L. Hagnauer, A. T. McManus, Nano Lett. 2001, 1, 18; (c) K. Esumi, A. Susuki, N. Aihara, K. Usui, K. Torigoe, Langmuir 1998, 14, 3157; (d) K. Esumi, K. Satoh, A. Suzuki, K. Torigoe, Shikizai Kyokaishi 2000, 73, 434; (e) K. Esumi, R. Isono, T. Yoshimura, Langmuir 2004, 20, 237.

20 (a) H.-F. Lang, R. A. May, B. L. Iversen, B. D. Chandler, J. Am. Chem. Soc. 2003, 125, 14832; (b) H.-F. Lang, S. Maldonado, K. J. Stevenson, B. D. Chandler, J. Am. Chem. Soc. 2004, 126, 12949; L. W. Beakley, S. E. Yost, R. Cheng, B. D. Chandler, Appl. Catal. A: General 2005, 292(1-2), 124; B. D. Chandler, J. D. Gilbertson, Top. Organomet. Chem., 2006, 20, 97; Dendrimer Catalysis, L. Gade (Ed.), Springer-Verlag, Berlin, 2006.

21 (a) Y. Li, M. A. El Sayed, J. Phys. Chem. B 2001, 105, 8938; (b) R. Narayanan, M. A. El-Sayed, J. Phys. Chem. B 2004, 108, 8572; (c) R. Narayanan, M. A. El-Sayed, Langmuir 2005, 21, 2027; R. Narayanan, M. A. El-Sayed, J. Catal. 2005, 234, 348.

22 (a) M. Pittelkow, K. Moth-Poulsen, U. Boas, J. B. Christensen, Langmuir 2003, 19, 7682; (b) M. Ooe, M. Murata, T. Mizugaki, K. Ebitani, K. Kaneda, Nano Lett. 2002, 2, 999; (c) K. Mori, T. Hara, T. Mizugaki, K. Ebitani, K. Kaneda, J. Am. Chem. Soc. 2004, 126, 10657; (d) K. R. Gopidas, J. K. Whitesell, M.-A. Fox, Nano Lett. 2003, 3, 1757.

23 Y.-M. Chung, H.-K. Rhee, J. Mol. Catal. A.: Chem. 2003, 206, 291.

24 (a) C. Rocaboy, J. A. Gladysz, Org. Lett. 2002, 4, 1993; (b) R. Grigg, L.-X. Zhang, S. Collard, A. Keep, Tetrahedron Lett. 2003, 44, 6979.

25 Polyoxometallate-stabilized metal NPs and their catalytic function: (a) J. D. Aiken III, 
R. G. Finke, J. Am. Chem.

Soc. 1999, 121, 8803; (b) S. Ozkar, R. G. Finke, J. Am. Chem. Soc. 2002, 124, 5796;

(c) A. M. Fargo, J. F. Odzak, F. S. Lai, B.

C. Gates, Nature 2002, 415, 623; (d) V.

Kogan, Z. Aizenshtat, R. Popovitz-Biro,

R. Neumann, Org. Lett. 2002, 4, 3529; (e)

M. Ohde, H. Yukiohde, C. M. Wai,

Chem. Commun. 2002, 2388; (f) anion-

mediated adsorption of tetra- $n$-butyl

ammonium cation on surfaces and metal

NPs: Z. Deng, D. E. Irish, J. Phys. Chem.

1994, 98, 11169; S. Özkar, R. G. Finke,

J. Am. Chem. Soc. 2002, 124, 5796; (g)

ealiest report of ammonium-stabilized

metal NPs: J. Kiwi, M. Grätzel, J. Am.

Chem. Soc. 1979, 101, 7214.

26 (a) L. Strimbu, J. Liu, A. E. Kaifer, Langmuir 2003, 19, 483; (b) J. Alvarez, J. Liu, E. Roman, A. E. Kaifer, Chem. Commun. 2000, 1151; (c) J. Liu, J. Alvarez, W. Ong, E. Roman, A. E. Kaifer, Langmuir 2001, 17, 6762.

27 F. Lu, J. Ruiz, D. Astruc, Tetrahedron Lett. 2004, 45, 9443.

28 (a) M.-K. Chung, G. Orlova, J. D. Goddart, M. Schlaf, R. Harris, T. J. Beveridge, G. White, F. R. Hallett, J. Am. Chem. Soc. 2002, 124, 10508; (b) M.-K. Chung, M. Schlaf, J. Am. Chem. Soc. 2004, 126, 7386; (c) S. U. Son, Y. Jang, J. Park, H. B. Na, H. M. Park, H. J. Yun, J. Lee, T. Hyeon, J. Am. Chem. Soc. 2004 , 126, 5026 and references cited therein.

29 K. Nasar, F. Fache, M. Lemaire, M. Draye, J. C. Béziat, M. Besson, P. Galez, J. Mol. Catal. 1994, 87, 107.

30 (a) H. Bönnemann, G. A. Braun, Chem. Eur. J. 1997, 3, 1200; (b) J. U. Köhler, J. S. Bradley, 1998, 14, 2730; (c) X. Zuo, H. Liu, D. Guo, X. Yang, Tetrahedron 1999, 45, 203; (d) M. Studer, H.-U. Blaser, C. Exner, Adv. Synth. Catal. 2003, 345, 45; (e) M. Tamura, H. Fujihara, J. Am. Chem. Soc. 2003, 125, 15742; (f) S. Jansat, M. Gomez, K. Philippot, G. Muller, E. Guiu, C. Claver, S. Castillon, B. Chaudret, J. Am. Chem. Soc. 2004, 126, 1592.

31 (a) T. Mizoroki, K. Mori, A. Ozaki, Bull. Chem. Soc. Jpn. 1971, 44, 581; (b) R. F. Heck, J. P. Nolley, Jr., J. Org. Chem. 1972, 37, 2320; (c) I. P. Beletskaya, A. V. Cheprakov, Chem. Rev. 2000, 100, 3009; (d) M. T. Reetz, E. Westermann, R. Lomer, G. Lohmer, Tetrahedron Lett. 1998, 39, 8449; (e) A. H. M. de Vries, J. M. C. A. Mulders, J. H. M. Mommers, H. J. W. Henderckx, J. G. de Vries, Org. Lett. 2003, 5, 3285; (f) M. T. Reetz, M. Maase, $A d v$. Mater. 1999, 11, 773; (g) C. Rocaboy, J. A. Gladysz, New J. Chem. 2003, 27, 39; (h) M. Nowotny, U. Hanefeld, H. van Koningsveld, T. Maschmeyer, Chem. Commun. 2000, 1877; (i) I. P. Beletskaya, A. N. Kashin, N. B. Karlstedt, A. V. Mitin, A. V. Chepakov, G. M. Kazankov, J. Organomet. Chem. 2001, 622, 89; (j) M. T. Reetz, E. Westermann, Angew. Chem. 2000, 112, 170; Angew. Chem. Int. Ed. 2000, 39, 165 (see also E. Westermann, Dissertation, Ruhr-Universität Bochum, 1999); (k) , T. Rosner, J. Le Bars, A. Pfaltz, D. G. Blackmond, J. Am. Chem. Soc. 2001, 123, 1848; (l) C. E. Williams, J. M. C. A. Mulders, J. G. de Vries, A. H. M. de Vries, J. Organomet. Chem. 2003, 687, 494; (m) J. G. de Vries, A. H. M. de Vries, Eur. J. Org. Chem. 2003, 799; (n) focus articles on ligand-free Heck reactions using extremely low Pd loading: A. H. M. de Vries, F. J.

Parlevliet, L. Schmeder-van de

Vondervoort, J. H. M. Mommers, H. J. W. Henderickx, M. A. N. Walet, J. de Vries, Adv. Synth. Catal. 2002, 344, 996; M. T. Reetz, J. G. de Vries, Chem. Commun. 2004, 1559; (o) N. T. S. Phan, M. Van der Sluys, C. J. Jones, Adv. Syn. Catal. 2006, 348, 609; (p) T. Sugihara, T. Satoh, M. Miura, Tetrahedron Lett. 2005, 46, 8269; E. Alacid, C. Nájera, Adv. Synth. Catal. 2006, 348, 945; R. Tatumi, T. Akita, H. Fujihara, Chem. Commun. 2006, 3349; I. Ryjomska, A. T. Trzeciak, J. J. Ziolkowski, J. Mol. Catal. A: Chem. 2006, 257, 3 (q) K. Pelzer, O. Vidoni, K. Philippot, B. Chaudret, V. Colliere, Adv. Funct. Mater. 2003, 13, 118; P. J. Dyson, D. J. Ellis, G. Laurenczy, Adv. Synth. Catal. 2003, 345, 211; J. A.

Widegren, R. G. Finke, J. Mol. Catal. A: Chem. 2003, 198, 317; Y. Na, S. Park, S. B. Han, H. Han, S. Ko, S. Chang, J. Am. Chem. Soc. 2004, 126, 250.

32 (a) I. T. Horvath, J. Rabai, Science 1994, 266, 72; I. T. Horvath, Acc. Chem. Res. 1998, 31, 641; L. P. Barthel-Rosa, J. A. Gladysz, Coord. Chem. Rev. 1999, 578, 190; (b) H. Ohde, C. M. Wai, H. Kim, M. Ohde, 
J. Am. Chem. Soc. 2002, 124, 4540; (c) P. Meric, K. M. K. Yu, S. C. Tsang, Catal. Lett. 2004, 95, 39; (d) P. Meric, K. M. K. $\mathrm{Yu}, \mathrm{S}$. C. Tsang, Langmuir 2004, 20, 8537; (e) K. M. K. Yu, C. M. Y. Yeung, D. Thompsett, S. C. Tsang, J. Phys. Chem. B 2003, 107, 4515; (f) B.-H. Yoon, H. Kim, C. M. Wai, Chem. Commun. 2003, 1040; (g) H. Ohde, C. M. Wai, H. Kim, J. Kim, M. Ohde, J. Am. Chem. Soc. 2002, 124, 4540; (h) X. R. Ye, Y-H. Lin, C. M. Wai, Chem. Commun. 2003, 642; (i) A. M. Doyle, S. K. Shaikhutdinov, S. D. David Jackson, H.-J. Freund, Angew. Chem. Int. Ed. 2003, 42, 5240; (j) J.-Z. Jiang, C. Cai, J. Coll. Interfac. Sci. 2006, 299, 938 (see also Ref. [43] for Scheme 8).

33 (a) Y. Chauvin, L. O. Mussmann, H. Olivier, Angew. Chem. Int. Ed. Engl. 1995, 34, 2698; (b) J. Dupont, R. F. de Souza, P. A. Z. Suarez, Chem. Rev. 2002, 102, 3667; (c) J. Dupont, G. S. Fonseca, A. P. Umpierre, P. F. P. Fitchtner, S. R. Teioxera, J. Am. Chem. Soc. 2002, 124, 4228; G. Schmid, M. Harm, J. Am. Chem. Soc. 1993, 115, 2047; (d) J. Huang, T. Jiang, H. Gao, Y. Chang, G. Zhao, W. Wu, Chem. Commun. 2003, 1654; (e) V. Calo, A. Nacci, A. Monopoli, S. Laera, N. Cioffi, J. Org. Chem. 2003, 68, 2929; (f) V. Calo, A. Nacci, A. Monopoli, A. Detomaso, P. Illiade, Organometallics 2003, 22, 4193; (g) M. Spiro, D. M. De Jesus, Langmuir 2000, 16, 2664 and 4896; G. Battistuzzi, S. Cacchi, G. Fabrizi, Synlett 2002, 439. (h) D. Zhao, Z. Fei, T. Geldbach, R. Scopelliti, P. J. Dyson, J. Am. Chem. Soc. 2004, 126, 15876;

(i) R. R. Deshmuhk, R. Rajagopal, K. V. Srinivasan, Chem. Commun. 2001, 1544; (j) L. Xu, W. Chen, J. Xiao,

Organometallics 2000, 19, 1123; (k) C. W. Scheeren, G. Machado, J. Dupont, P. F. P. Fichtner, S. R. Texeira, Inorg. Chem. 2003, 42, 4738; (1) E. T. Silveira, A. P. Umpierre, L. M. Rossi, G. Machado, J. Morais, G. V. Soares, I. J. R. Baumvol, S. R. Teixeira, P. F. P. Fichtner, J. Dupont, Chem. Eur. J. 2004, 10, 3734; (m) G. S. Fonseca, J. D. Scholten, J. Dupont, Synlett 2004, 9, 1525; (n) C. S. Consorti, F. R. Flores, J. Dupont, J. Am. Chem. Soc. 2005, 127, 12054.
34 (a) C. E. Tucker, J. G. de Vries, Top. Catal. 2002, 19, 111; (b) M. Beller, A. Zapf, in Handbook of Organopalladium Chemistry for Organic Synthesis, Vol. 1, E.-i. Negishi (Ed.), Wiley, Hoboken, 2002, p. 1209; (c) P. Baumeister, W. Meyer, K. Oertle, G. Seifert, H. Seifert, H. Steiner, Chimia, 1997, 51, 144; (d) J. McChesney, Spec. Chem. 1999, 6, 98.

35 (a) J. P. M. Niederer, A. B. J. Arnold, W. F. Hölderich, B. Tesche, M. Reetz, H. Bönnemann, Top. Catal. 2002, 18, 265; (b) S.-W. Kim, M. Kim, W. Y. Lee, T. Hyeon, J. Am. Chem. Soc. 2002, 124, 7642; (c) K. H. Park, S. U. Son, Y. K. Chung, Org. Lett. 2002, 4, 4361; (d) R. Abu-Reziq, D. Avnir, J. Blum, J. Mol. Catal. A. 2002, 187, 277; (e) A. Horvath, A. Beck, Z. Koppany, A. Sarkany, L. Guczi, J. Mol. Catal. A. 2002, 182, 295; (f) A.-M. Huang, Z.-F. Liu, C. Lai, J.-D. Hua, J. Appl. Polym. Sci. 2002, 85, 989; (g) A. Molnar, A. Papp, K. Miklos, P. Forgo, Chem. Commun. 2003, 2626; (h) T. Sanji, Y. Ogawa, Y. Nakatsuka, M. Tanaka, H. Sakurai, Chem. Lett. 2003, 32, 980; (i) O. Dominguez-Quintero, S. Martinez, Y. Henriquez, L. D'Ornelas, H. Krentzien, J. Osuna, J. Mol. Catal. A. 2003, 197, 185; (j) I. Yuranov, P. Moeckli, E. Suvorova, P. Buffat, L. Kiwi-Minsker, A. Renken, J. Mol. Catal. A. 2003, 192, 239; (k) B. Corain, P. Guerriero, G. Schiavon, M. Zapparoli, M. Kralik, J. Mol. Catal. A. 2004, 211, 237; M. Kralik, V. Ktratky, P. Centomo, P. Guerriero, S. Lora, B. Corain, J. Mol. Catal. A: Chem. 2003, 195, 219;

(1) P. Canton et al. Catal. Lett. 2003, 88, 141; (m) V. Johank et al. Surf. Sci. 2004, 561, L218; (n) T. G. Galow, U. Dreshler, J. A. Hanson, V. M. Rotello, Chem. Commun. 2002, 1076; (o) R. B. Bedford, U. G. Singh, R. I. Walton, R. T. Williams, S. A. Davis, Chem. Mater. 2005, 17, ASAP.

36 (a) H.-P. Kormann, G. Schmid, K. Pelzer, K. Philippot, B. Chaudret, Z. Anorg. Allg. Chem. 2004, 630, 1913; (b) M. Yashima, L. K. L. Falk, A. E. C. Palmqvist, K. Holmberg, J. Colloid Interfac. Sci. 2003, 268, 348; (c) S. Schauermann, J. Hoffmann, V. Johanek, J. Hartmann, J. Libuda, H.-J. Freund, Angew. Chem. 2002, 114, 2643; Angew. Chem. Int. Ed. 2002, 41, 2532; (d) M. Heemeier, A. F. Carlsson, M. Naschitzki, M. Schmal, M. Bäümer, H.-J. 
Freund, Angew. Chem. 2002, 114, 4242; Angew. Chem. Int. Ed. 2002, 41, 4073; (e) V. Johanek, M. Laurin, J. Hoffmann, S. Schauermann, A. W. Grant, B. Kasemo, J. Libuda, H.-J. Freund, Surf. Sci. 2004, 561, L218.

37 (a) K. Ebitani, Y. Fujie, K. Kaneda, Langmuir 1999, 1907; K. Kaneda, M. Higushi, T. Himanaka, J. Mol. Cat. A: Chem. 2001, 63, L33; (b) K.-M. Choi, T. Akita, T. Mizugaki, K. Ebitani, K. Kaneda, New J. Chem. 2003, 27, 324; (c) L. Guczi, A. Beck, A. Horvath, Zs. Koppany, G. Stefler, K. Frey, I. Sajo, O. Geszti, J. Lynch, J. Mol. Catal. A. 2004, 204, 545.

38 K. Mori, T. Hara, T. Mizugaki, K. Ebitani, K. Kaneda, J. Am. Chem. Soc. 2004, 126, 10657.

39 (a) T. Nishimura, N. Kakiuchi, M. Inoue, S. Uemura, Chem. Commun. 2000, 1245; (b) N. Kakiuchi, Y. Maeda, T. Nishimura, S. Uemura, J. Org. Chem. 2001, 66, 6220; (c) S. Schauermann, J. Hoffmann, V. Johanek, J. Hartmann, J. Libuda, H.-J. Freund, Angew. Chem. Int. Ed. 2002, 41, 2532; (d) M. Heemeier, A. F. Carlsson, M. Naschitzki, M. Schmal, M. Bäümer, H.-J. Freund, Angew. Chem. Int. Ed. 2002, 41, 4073; (e) B. M. Choudary, S. Mahdi, N. S. Chowdari, M. L. Kantam, B. Streedhar, J. Am. Chem. Soc. 2002, 124, 14127; (f) A. Mastalir, Z. Kiraly, J. Catal. 2003, 220, 372; (g) A. Mastalir, Z. Kiraly, J. Catal. 2003, 220, 372; (h) S. Bertarione, D. Scarano, A. Zecchina, V. Johanek, J. Hoffmann, S. Schauermann, J. Libuda, G. Rupprechter, H.-J. Freund, J. Catal. 2004, 223, 64; (i) P. Pfeifer, K. Schubert, M. A. Liauw, G. Emig, Appl. Catal. A 2004, 270, 165.

40 G. Riahi, D. Guillemot, M. PolissetTfoin, A. A. Khodadadi, J. Fraissard, Catal. Today, 2002, 72, 115; M. Mtelkar, C. V. Rode, R. V. Chaudhari, S. S. Joshi, A. M. Nalawade, Appl. Catal. A: General 2004, 273, 11.

41 (a) N. Toshima, Y. Shiiraishi, T. Teranishi, M. Mitake, T. Tominaga, H. Watanabe, W. Brijoux, H. Bönnemann, G. Schmid, Appl. Organomet. Chem. 2001, 15, 178; (b) J. Huang, T. Jiang, H.X. Gao, B.-X. Han, Z.-M. Liu, W.-Z. Wu,
Y.-H. Chang, G.-Y. Zhao, Angew. Chem. Int. Ed. 2004, 43, 1397 (c) M. T. Reetz, H. Schulenburg, M. Lopez, B. Spliethoff, B. Tesche, Chimia 2004, 58, 896.

42 (a) F. Caruso, Adv. Mater. 2001, 13, 11; F. Caruso, R. A. Caruso, H. Möhhwald, Science 1998, 282, 1111; Y. Lin, Y. Lu, B. Gates, Y. Xia, Chem. Mater. 2001, 13, 1146; M. Julia, M. Duteil, C. Grard, E. Kunz, Bull. Soc. Chim. Fr. 1993, 2791; (b) M. Julia, M. Duteil, Bull. Soc. Chim. Fr. 1993, 2791; (c) A. F. Shmidt, L. V. Mametova, Kinet. Katal. 1996, 37, 406; (d) F. Zhao, M. Arai, React. Kinet. Catal. Lett. 2004, 81, 281; F. Zhao, B. M. Bhanage, M. Shirai, M. Arai, Chem. Eur. J. 2000, 6, 843; see also Arai's Refs. [73 c,g, 86a-c].

43 (a) M. Wagner, K. Köhler, L. Djakovitch, M. Mühler, Top. Catal. 1999, 13, 319; (b) K. Köhler, L. Djakovitch, M. Wagner, Catal. Today, 2001, 66, 105; (c) L. Djakovitch, K. Köhler, J. Am. Chem. Soc. 2001, 123, 5990; (d) A. Nejjar, C. Pinel, L. Djakovitch, Adv. Synth. Catal. 2003, 345, 612; (e) L. Djakovitch, M. Wagner, C. G. Hartung, M. Beller, K. Köhler, J. Mol. Catal. A: Chem., 2004, 219, 121; (f) S. Pröckl, W. Kleist, M. A. Gruber, K. Köhler, Angew. Chem. Int. Ed. Engl. 2004, 43, 1881; (g) L. Djakovitch, P. Rollet, Adv. Syn. Catal. 2004, 346, 1782; (h) L. Djakovitch, P. Rollet, Tetrahedron Lett. 2004, 45, 1367; (i) S. Chouzier, M. Gruber, L. Djakovitch, J. Mol. Catal. A: Chem. 2004, 212, 43; (j) J. Penzien, C. Haessner, A. Jentys, K. Köhler, T. E. Muller, J. A. Lercher, J. Catal. 2004, 221, 302; (k) J. P. Collman, K. M. Kosydar, M. Bressan, W. Lamanna, T. Garrett, J. Am. Chem. Soc. 1984, 106, 2569; J. Rebek, Tetrahedron, 1979, 35, 723; I. W.

Davies, L. Matty, D. L. Hugues, P. J. Reider, J. Am. Chem. Soc. 2001, 123, 10139 (for a recent detailed analysis of this test in the context of Pd catalysis, see Jones' review [31o]).

44 (a) P. W. Albers, J. G. E. Krauter, D. K. Ross, R. G. Heiodenreich, K. Köhler, S. F. Parker, Langmuir, 2004, 20, 8254;

(b) P. Rylander. Catalytic Hydrogenation in Organic Synthesis, Academic Press, New York, 1979; (c) M. L. Toebes, J. A. van Dillen, K. P. de Jong, J. Mol. Catal. A: Chem. 2001, 173, 75; (d) C. R. Le Blond, 
A. T. Andrews, Y. Sun, J. R. Sowa, Jr., Org. Lett 2001, 3, 1555; (e) E. B. Mobufu, J. H. Clark, D. J. Macquarrie, Green Chem. 2001, 3, 23; (f) R. G. Heidenreich, J. G. E. Krauter, J. Pietsch, K. Köhler, J. Mol. Catal. A: Chem. 2002, 182-183, 499; K. Köhler, R. G. Heidenreich, J. G. E. Krauter, J. Pietsch, Chem. Eur. J. 2002, 8, 622; (g) F. Zhao, K. Kurakami, M. Shirai, M. Arai, J. Catal. 2000, 194, 479; (h) B. Coq, F. Figueras, P. Geneste, C. Moreau, P. Moreau, M. Warawdekar, J. Mol. Catal. 1993, 78, 211; A. Cwik, Z. Hell, F. Figueras, Org. Biol. Chem. 2006, 3, 4307; A. Cwik, Z. Hell, F. Figueras, Tetrahedron Lett. 2006, 47, 3023; (i) V. A. Yakovlev, V. V. Terskikh, V. I. Simagina, V. A. Likholobov, J. Mol. Catal. A 2000, 153, 231; (j) P. Styring, C. Grindon, C. M. Fisher, Catal. Lett. 2001, 77, 219; (k) B. H. Lipshutz, S. Tasler, W. Chrisman, B. Spliethoff, B. Tesche, J. Org. Chem. 2003, 68, 1177; (1) B. H. Lipshutz, J. A. Sclafani, P. A. Blomgren, Tetrahedron, 2000, 56, 2139; (m) B. H. Lipshutz, P. A. Blomgren, J. Am. Chem. Soc. 1999, 121, 5819; (n) B. H. Lipshutz, Adv. Synth. Catal. 2001, 343, 313; (о) B. H. Lipshutz, H. Ueda, Angew. Chem. 2000, 112, 4666; Angew. Chem. Int. Ed. 2000, 39, 4492; (p) F. Zaera, Acc. Chem. Res. 2002, 35, 129. K. Anderson, S. C. Fernandez, C. Hardacre, P. C. Marr, Inorg. Chem. Commun. 2004, 7, 73; (q) S. Carrettin, J. Guzman, A. Corma, Angew. Chem. Int. Ed. 2005, 44, 2242; J. Gurman, S. Carretin, A. Corma, J. Am. Chem. Soc. 2005, 127, 3286; A. Corma, H. Garcia, A. Leyva, J. Catal. 2006, 240, 87; A. Corma, H. Garcia, A. Leyva, J. Mol. Catal. A: Chemical 2005, 230, 97; (r) G. G. Wildgoose, C. E. Banks, R. G. Compton, Small 2006, 2, 182.

45 45. (a) For AuNP-catalyzed CO oxidation by $\mathrm{O}_{2}$, see Chapter 15 , Haruta's reviews in Refs. [9e, 11j, 50b] and G. J. Hutchings, Catal. Today 2005, 100, 55.

46 For oxide-AuNP-catalyzed oxidation reactions, see Ref. [3] and Chapters 1215. For specific reactions, see: (a) S. Okumura, S. Nakamara, T. Tsubota, M. Nakamura, M. Azuma, Catal. Lett. 1998, 51, 53; M. Okumura, T. Akita, M.
Haruta, Catal. Today 2002, 74, 265; (b) C. Mohr, H. Hofmeister, P. Claus, J. Catal. 2003, 213, 86; (c) S. Biella, M. Rossi, Chem. Commun. 2003, 378; S. Biela, G. L. Castiglioni, C. Fumagalli, L. Prati, M. Rossi, Catal. Today 2002, 72, 43; (d) C. Milone, R. Ingoglia, G. Neri, A. Pistone, S. Galvagno, Appl. Catal. A 2001, 211, 251; C. Milone, M. L. Tropeano, G. Gulino, G. Neri, R. Ingoglia, S. Galvano, Chem. Commun. 2002, 868; (e) P. Landon, P. J. Collier, A. J. Papworth, C. J. Kiely, G. J. Hutchings, Chem. Commun. 2002, 2058; (f) F. Shi, Y. Deng, J. Catal. 2002, 211, 548; S.-W. Kim, S. U. Son, S. S. Lee, T. Hyeon, Y. K. Chung, Chem. Commun. 2001, 2212; (g) G. Lue, D. Ji, G. Qian, Y. Qi, X. Wang, J. Suo, Appl. Catal., A: General, 2005, 280, 175; (h) K. Zhu, J. Hu, R. Richards, Catal. Lett. 2005, 100, 195.

47 M. M. Maye, J. Luo, Y. Lin, M. H. Engelhard, H. Mark, M. Hepel, C.-J. Zhong, Langmuir 2003, 19, 125 and references cited therein; C. Roth, I. Hussain, M. Bayati, R. J. Nichols, D. J. Schiffrin, Chem. Commun. 2004, 1532; H. Tang, J. H. Chen, M. Y. Wang, L. H. Nie, Y. F. Kuang, S. Z. Yao, Appl. Catal. A 2004, 275, 43; for a recent review, see Ref. [8a]; Z. Liu, X. Y. Ling, X. Su, J. Y. Lee, J. Phys. Chem. B 2004, 108, 8234; J. SollaGullon, F. J. Vidal-Iglesias, V. Montiel, A. Aldaz, Electrochem. Acta 2004, 49, 5079; X. Zhang, F. Zhang, K.-Y. Chan, J. Mater. Sci. 2004, 39, 5845; Z. He, J. Chen, D. Liu, H. Zhou, Y. Kuang, Diamond Relat. Mater. 2004, 13, 1764; E. V. Spinace, A. O. Neto, M. Linardi, J. Power Sources 2004, 129, 121; C. Bock, C. Paquet, M. Couillard, G. A. Botton, B. R. MacDougall, J. Am. Chem. Soc. 2004, 126, 8028; K. Zhu, J. Hu, R. Richards, Catal. Lett. 2005, 100, 195; G. M. Veith, A. R. Lupini, S. J. Pennycook, G. W. Ownby, N. J. Dudney, J. Catal. 2005, 231, 151; S.-H. Baeck, T. F. Jaramillo, A. Kleiman, E. W. McFarland, Measur. Sci. Technol. 2005, 16, 54.

48 I. Shinkai, A. O. King, R. D. Larsen, Pure Appl. Chem. 1994, 66, 1551; A. P. Philipse, M. P. B. van Bruggen, C. Pathmamanoharan, Langmuir 1994, 10, 92; W. Teunissen, M. F. de Groot, J. Geus, O. Stephan, M. Tence, C. Colliex, J. Catal. 
2001, 204, 169; P. Tarjaj, C. J. Serna, J. Am. Chem. Soc. 2003, 125, 15754; A.-H. Lu, W. Schmidt, N. Matoussevitch, H. Bönnemann, B. Spliethoff, B. Tesche, E. Bill, W. Kiefer, u. F. Schüth, Angew. Chem. Int. Ed. 2004, 43, 4303; S. C. Tsang, V. Caps, I. Paraksevas, D. Chadwick, D. Thompsett, Angew. Chem. Int. Ed. 2004, 43, 5645; P. Wang Xiao, B. Shen, N. He, Colloid Surf. A: Physicochem. Eng. Asp. 2006, 276, 116.

49 (a) G. Schmid, H. West, H. Mehles, A. Lehnert, Inorg. Chem. 1997, 36, 891; A. M. Caporusso, L. A. Aronica, E. Schiavi, G. Martra, G. Vitulli, P. Salvadori, J. Organomet. Chem. 2005, 690, 1063; (b) C. Larpent, F. Brisse-Le Menn, H. Patin, New. J. Chem. 1991, 15, 361; C. Larpent, F. Brisse-Le Menn, H. Patin, J. Mol. Catal. 1991, 65, L35; C. Larpent, E. Bernard, F. Brisse-Le Menn, H. Patin, J. Mol. Catal. A: Chem. 1997, 116, 277; F. Launay, H. Patin, New J. Chem. 1997, 21, 247; F. Launay, A. Roucoux, H. Patin, Tetrahedron Lett. 1998, 39, 1353; see also ref. 11e.

50 D. Soulivong, C. Copéret, J. ThivolleCazat, J.-M. Basset, B. Maunders, R. B. A. Pardy, G. J. Sunley, Angew. Chem. Int. Ed. 2004, 43, 5366; C. Copéret, F. Lefebvre, J.-M. Basset, in Handbook of Metathesis, R. H. Grubbs (Ed.), WileyVCH, Weinheim, 2003, Vol. 1, Ch. 1.12, pp.190-2004.

51 M. Haruta, Stud. Surf. Sci. Catal. 2003, 14 (Sci. Technol. Catal. 2002, 31); H. Tang, J. H. Chen, M. Y. Wang, L. H. Nie, Y. F. Kuang, S. Z. Yao, Appl. Catal. A 2004, 275, 43; A. K. Sinha, S. Seelan, M. Okumura, T. Akita, S. Tsubota, M. Haruta, J. Phys. Chem. B 2005, 109, 3956.

52 H. Bönnemann, W. Brijoux, A. Schulze Tilling, K. Siepen, Top. Catal. 1997, 4, 217; H. Bönnemann, W. Brijoux, R. Brinkmann, A. Schulze Tilling, K. Siepen, H. Bönnemann, W. Brijoux, A. Schulze Tilling, T. Shilling, B. Tesche, K. Seevogel, R. Franke, J. Hormes, G. Köhl, J. Pollmann, J. Rothe, W. Vogel, Inorg. Chim. Acta 1998, 270, 95.

53 (a) Q. Wang, H. Liu, M. Han, X. Li, D. Jiang, J. Mol. Catal. A: Chem. 1997, 118,
145; (b) M. Beller, H. Fischer, K. Köhlein, C.-P. Reisinger, W. A. Herrmann, J. Organomet. Chem. 1996, 520, 257.

54 M. T. Reetz, R. Breinbauer, K. Wanninger, Tetrahedron Lett. 1996, 37, 4499.

55 M. T. Reetz, R. Breinbauer, P. Wedemann, P. Binger, Tetrahedron 1998, 54, 1233.

56 M. T. Reetz, S. A. Quaiser, C. Merk, Chem. Ber. 1996, 129, 741.

57 K. Manabe, Y. Mori, T. Wakabayashi, S. Nagayama, S. Kobayashi, J. Am. Chem. Soc. 2000, 122, 7202.

58 A. B. R. Mayer, J. E. Mark, R. E. Morris, Polym. J. 1997, 275, 333; A. Borsla, A. M. Wilhelm, H. Delmas, Catal. Today 2001, 66, 389.

59 (a) W. Liu, H. Liu, X. An, X. Ma, Z. Liu, L. Quiang, J. Mol. Catal. A: Chem. 1999, 147, 73 and refs cited therein. (b) W. Yu, H. Liu, M. Liu, Z. Liu, React. Funct. Polym. 2000, 44, 21. (c) X. Yang, Z. Deng, H. Liu, J. Mol. Cat. A Chem. 1999, 144, 123.

60 N. Pradhan, A. Pal, T. Pal, Langmuir 2001, 17, 1800.

61 H. Hirai, N. Yakura, Y. Seta, S. Hodoshima, React. Funct. Polym. 1998, 37, 121.

62 G. Schmid, V. Maihack, F. Lantermann, S. Peschel, J. Chem. Soc., Dalton Trans. 1996, 589.

63 H. Bönnemann, G. A. Braun, Angew. Chem. Int. Ed. 1996, 35, 1992.

64 P. Drogna-Landré, M. Lemaire, D. Richard, P. Gallezot, J. Mol. Catal. 1993, 78, 257; P. Drogna-Landré, D. Richard, M. Draye, P. Gallezot, M. Lemaire, J. Catal. 1994, 147, 214.

65 W. D. Harman, Chem. Rev. 1997, 97, 1953.

66 Y. Lin, R. G. Finke, Inorg. Chem. 1994, 33, 4891.

67 (a) H. Yang, H. Gao, R. Angelici, Organometallics 2000, 19, 622; (b) J.-L. Pellegatta, C. Blancy, V. Collière, R. Choukroun, B. Chaudret, P. Cheng, K. Philippot, J. Mol. Catal. A: Chemical 2002, 178, 55.

68 J. Blum, I. Amer, A. Zoran, Y. Sasson, Tetrahedron Lett. 1983, 24, 4139; J. Foise, R. Kershaw, K. Dwight, A. Wold, Mater. Res. Bull. 1985, 20, 147.

69 R. W. Albach, M. Jautelat, in Two-Phase Hydrogenation Method and Colloidal 
Catalysts for the Preparation of Cyclohexanes from Benzenes, 1999, Ger. Offen. (A. G. Bayer), Germany.

70 J. Schulz, A. Roucoux, H. Patin, Chem. Commun. 1999, 535; J. Schulz, A. Roucoux, H. Patin, Chem. Eur. J. 2000, 6, 618; J. Schulz, S. Levigne, A. Roucoux, H. Patin, Adv. Synth. Catal. 2002, 344, 266; A. Roucoux, J. Schulz, H. Patin, Adv. Synth. Catal. 2003, 345, 222; V. Mévellec, A. Roucoux, E. Ramirez, K. Philippot, B. Chaudret, Adv. Synth. Catal. 2004, 346, 72.

71 T. Jeffery, Tetrahedron 1996, 52, 10113.

72 S. Klingelhöfer, W. Heitz, A. Greiner, S. Oestreich, S. Förster, M. Antonietti, J. Am. Chem. Soc. 1997, 119, 10116; J. Walter, J. Heiermann, G. Dyker, S. Hara, H. Shioyama, J. Catal. 2000, 189, 449; B. M. Choudary, N. S. Chowdari, K. Jyoti, N. S. Kumar, M. L. Kantam, Chem. Commun. 2002, 586; J. Le Bars, U. Sprecht, J. S. Bradley, D. G. Blackmond, Langmuir 1999, 15, 7621; M. Moreno-Manas, R. Pleixats, S. Villaroya, Organometallics 2001, 20, 4524.

73 For recent reviews on Heck reaction, see Ref. [31c,n] and: S. Bräse, A. de Meijere, in Metal-Catalyzed Cross-Coupling Reactions, F. Diederich, P. J. Stang (Eds.), Wiley-VCH, Weinheim, 1998, pp. 99166; I. P. Beletskaya, A. V. Cheprakov, Chem. Rev. 2000, 100, 3009; N. J. Whitcombe, K. K. Hii, S. E. Gibson, Tetrahedron 2001, 57, 7449; B. M. Bhanage, M. Arai, Catal. Rev. 2001, 43, 315; A. F. Littke, G. C. Fu, Angew. Chem. Int. Ed. 2002, 41, 4176; A. Hillier, P. Nolan, Plat. Met. Rev. 2002, 46, 50; A. F. Little, G. C. Fu, Angew. Chem. 2002, 114, 4350; Angew. Chem. Int. Ed. 2002, 41, 4176; M. Larhed, A. Hallberg, in Handbook of Organopalladium Chemistry for Organic Synthesis, Vol. 1, E.-I. Negishi (Ed.), Wiley, Hoboken, 2002, p. 1133; W. Hieringer, in Applied Homogeneous Catalysis with Organometallic Compounds, Vol. 2, 2nd edn., B. Cornils, W. A. Herrmann (Eds.), Wiley-VCH, Weinheim, 2002, p. 721; B. M. Bhanage, S.-i. Fujita, M. Arai, J. Organomet. Chem.
2003, 687, 211; M. Shibasaki, E. M. Vogl, T. Oshima, in Comprehensive Asymmetric Catalysis, Vol. sup. 2004, E. N. Jacobsen, A. Pfaltz, H. Yamamoto, (Eds.), Springer Verlag, Heidelberg, 2004, p. 73; J. Tsuji, Palladium Reagents and Catalysis, Wiley, West Sussex, 2004; Handbook of Organopalladium Chemistry for Organic Synthesis, Negishi, E. (Ed.), Wiley, Hoboken, 2002; K. Ferré-Filmon, L. Delaude, A. Demonceau, A. F. Noels, Coord. Chem. Rev. 2004, 248, 2323.

74 (a) For a recent review on the Suzuki reaction, see: A. Suzuki in Modern Arene Chemistry, D. Astruc (Eds.), Wiley-VCH, Weinheim, 2003, pp. 53-106; (b) for a recent review on amination of aryl halides and sulfonates, see: J. F. Hartwig in Modern Arene Chemistry, D. Astruc (Eds.), Wiley-VCH, Weinheim, 2003, pp. 107-168.

75 F. Bertoux, E. Monflier, Y. Castanet, A. Mortreux, J. Mol. Cat. A 1999, 143, 23.

76 M. T. Thathagar, J. Beckers, G. Rothenberg, J. Am. Chem. 2002, 124, 11858; A. F. Thathagar, P. J. Kooyman, R. Boerleider, E. Jansen, C. J. Elsevier, G. Rothenberg, Adv. Synth. Catal. 2005, 347, 1965; M. B. Thathagar, J. E. ten Elshof, G. Rothenberg, Angew. Chem. Int. Ed. 2006, 45, 2886; L. D. Pachón, C. J. Elsevier, G. Rothenberg, Adv. Synth. Catal. 2006, 348, 1705.

77 L. Djakovitch, M. Wagner, K. Kohler, J. Organomet. Chem. 1999, 592, 225; B. H. Lipshutz, H. Ueda, Angew. Chem. Int. Ed. 2000, 39, 4492.

78 C. Mohr, H. Hofmeister, J. Radnik, P. Claus, J. Am. Chem. Soc. 2003, 125, 1905; K. Chen, Z. Zhang, Z. Cui, D. Yang, Gaofenzi Xuebao 2000, 180, Chem. Abstr. 133, 159490.

79 S. Scire, S. Minico, C. Crisafulli, C. Satriano, A. Pistone, Appl. Catal. B 2003, 40, 43.

80 C. T. Campbell, Science 2004, 306, 234.

81 (a) H. Berndt, A. Martin, I. Pitsch, U. Prusse, K.-D. Vorlop, Catal. Today 2004, 91, 191; S. Carrettin, P. McMorn, P. Johnston, K. Griffin, C. J. Kiely, G. A. Attard, G. J. Hutchings, Top. Catal. 2004, 27, 131; (b) S. Biella, F. Porta, L. Prati, 
M. Rossi, Catal. Letters 2003, 90, 23; (c)

A. Venugopal, M. S. Scurrel, Appl. Catal.,

A: General 2004, 258, 241.

82 (a) R. L. Augustine, S. T. O'Leary, J. Mol. Catal. A: Chem. 1995, 277, 95; (b) J. Le
Bars, U. Specht, J. S. Bradley, D. G. Blackmond, Langmuir 1999, 15, 7621; (c) B. M. Choudary, S. Madhi, N. S. Chowdari, M. L. Kantam, B. Sreedhar, J. Am. Chem. Soc. 2002, 124, 14127. 